\title{
DETERMINAÇÃO DOS PARÂMETROS DA DISTRIBUIÇÃO GAMA E MÉDIA PLUVIOMÉTRICA DECENDIAL PARA ESTAÇÕES DO ESTADO DE MATO GROSSO
}

\author{
SEVERINO DE PAIVA SOBRINHO, VICTOR ARLINDO TAVEIRA DE MATOS, ANA PAULA \\ MEIRA SOARES PEREIRA, FERNANDO PIVETTA, GUILHERME BARROS SEIXAS, JOSE \\ HOLANDA CAMPELO JUNIOR
}

\author{
Universidade Federal de Mato Grosso (UFMT), Cuiabá, MT, Brasil \\ paivasevero@unemat.br, victor_arlindo@hotmail.com, anapaula.ufmt@yahoo.com.br, nand_ao@hotmail.com, \\ guilherme.seixas@cba.ifmt.edu.br, campelo@ufmt.br
}

Recebido Novembro de 2012 - Aceito Abril de 2013

\begin{abstract}
RESUMO
O estado de Mato Grosso está entre os maiores produtores de grãos do Brasil sendo responsável por parte das mercadorias que o país exporta, sendo estas dependentes das precipitações pluviométricas. Em virtude destes fatos no presente trabalho objetivou-se a utilização da Distribuição Gama (2 parâmetros) para a descrição probabilística dos totais decendiais de precipitação média em 43 estações, de modo a fornecer informações que permitam estimar a precipitação mínima esperada com uma determinada probabilidade. Observou-se que os valores de chuva apresentam elevada variabilidade espaço-temporal ao longo do estado. As estimativas do parâmetro de forma $(\gamma)$ e de escala $(\beta)$ variaram de 0,01 a 120,7 e de 0,01 a 336, respectivamente. Os parâmetros $\gamma$ e $\beta$ da Distribuição Gama podem ser utilizados para determinação de precipitação decendial esperada e os decêndios com maiores precipitações estão entre os meses de novembro a março, sendo o maior valor 186,2 mm no município de Aripuanã. As estações mais ao norte do estado apresentam os decêndios com as maiores precipitações, enquanto aquelas mais ao sul tiveram valores menores.
\end{abstract}

Palavras-chave: precipitação, variabilidade pluviométrica, estimativa de parâmetros.

ABSTRACT: DETERMINATION OF PARAMETERS OF GAMMA DISTRIBUTION AND AVERAGE RAINFALL 10 DAYS STATIONS FOR THE MATO GROSSO OF STATE

Mato Grosso is among the largest grain producers of Brazilian's States and it is responsible for some of the commodities that the country exports and these are dependent on rainfall. Considering these facts, the present study aimed to determine the parameters of the Gamma distribution probability related to precipitation measurements on 43 stations, in periods of ten days, to provide information to estimate the probability of a minimum expected 10 days precipitation. A great spatial and temporal variability of the measured 10 days precipitation along the State was reported. Estimates of the shape $(\gamma)$ and scale $(\beta)$ parameters varied from 0.01 to 120.7 and from 0.01 to 336.0 respectively. The parameters " $\gamma$ " and " $\beta$ " of the Gamma Distribution can be used to determining the expected 10 days precipitation, and the periods with higher rainfall, are between the months from November to March. The Northward stations of the State have the greatest 10 days precipitation while those Southward, have lower values.

Keywords: rainfall, rainfall variability, parameter estimation. 


\section{INTRODUÇÃO}

A precipitação pluvial é um dos elementos meteorológicos que tem forte influência sobre as condições ambientais, influenciando as atividades agrícolas, principalmente sobre o desenvolvimento e a produtividade das culturas agrícolas (Dallacort et al., 2008). Umas das preocupações quanto às chuvas é a intensidade e a frequência de suas ocorrências, pelos seus efeitos potencialmente danosos quando em excesso ou por escassez (Murta et al., 2005).

Para Queiroz et al. (2001), ter conhecimentos sobre o regime pluviométrico de uma região é fundamental para a tomada de decisões nas diversas áreas de produção. Nas áreas com produção agrícola, os efeitos adversos oriundos da falta de regularidade na precipitação pluvial trazem como resultado quebras na produção, que algumas vezes podem levar a uma perda total da produção (Ely et al., 2010). O conhecimento prévio e confiável do regime pluviométrico para o planejamento agrícola poderá reduzir significativamente os riscos de prejuízos nas atividades agropecuárias (Dallacort et al., 2011).

A precipitação pluvial pode ser estimada de várias formas, e uma delas é a utilização de termos probabilísticos mediante modelos teóricos de distribuição ajustados a uma série de dados. Uma vez gerado os modelos, os mesmos são submetidos à comprovação da aderência dos dados à distribuição teórica podendo fornecer informações úteis para o planejamento de muitas atividades (Fietz et al., 1997). O modelo de Distribuição Gama é largamente utilizado para a estimativa de probabilidades e na simulação de dados climáticos (Thom, 1958; Murta et al., 2005; Moreira et al., 2010, Dallacort et al., 2011; Martins et al., 2011).

Diversos trabalhos têm mostrado que a Distribuição Gama pode ser utilizada para representar adequadamente o regime da precipitação pluviométrica, dentre os quais podem ser citados aqueles realizados por Thom (1958), Krepper et al. (1989), Fietz et al. (1998), Murta et al. (2005), Moreira et al. (2010), Dallacort et al. (2011) e Martins et al. (2011).

Com base no exposto, neste trabalho objetivou-se determinar, na escala decendial, os parâmetros de forma e escala da Distribuição Gama ( $\gamma$ e $\beta$, respectivamente) de estações pluviométricas de Mato Grosso, e obter informações que permitam a determinação da precipitação mínima esperada, para qualquer frequência esperada, verificar em quais meses do ano estão os maiores desse elemento meteorológico e observar se o período chuvoso e quantidade de chuva são semelhantes em todo estado.

\section{MATERIAL E MÉTODOS}

Os dados de precipitação utilizados no desenvolvimento do presente trabalho foram disponibilizados pela Agência
Nacional de Águas (ANA), com histórico de dados variando 10 a 80 anos (Tabela 1) e as informações gerais sobre as estações estão representadas na Tabela 1.

Para avaliar a consistência dos dados decendiais, os mesmos foram analisados com base nos testes da mediana (série sem interrupções), Wald-Wolfowitz (com uma interrupção na série) ou Kruskal-Wallis (duas ou mais interrupções na série). Os testes não paramétricos foram realizados com auxílio do software estatístico SPSS.

Para as séries consistentes, procedeu-se a ordenação dos dados de modo crescente, e, pelo método de Weibull (Wilks, 2006), estimou-se a probabilidade acumulada dos totais decendiais. Em seguida, esses totais decendiais foram ajustados a um modelo misto de probabilidade (Assis et al., 1996), correspondente à soma da probabilidade de ocorrência de valores nulos (zeros), com a probabilidade obtida com o modelo probabilístico da Distribuição Gama incompleta, descrito por Thom (1958), onde sua função de densidade de probabilidade é dada pela equação:

$$
G(y)=\frac{1}{\beta^{\gamma} \Gamma(\gamma)} * \int_{0}^{y} e^{\frac{-y}{\beta}} y^{\gamma-1} d y
$$

em que: $\gamma$ é o parâmetro de forma (adimensional), $\beta$ o parâmetro de escala (mm), $\Gamma$ o símbolo da função gama e $y$ a precipitação em mm. Os parâmetros $\gamma$ e $\beta$ que possibilitam o cálculo da Distribuição Gama incompleta para uma dada variável aleatória foram estimados pelo método da máxima verossimilhança (Assis et al., 1996), conforme as equações:

$$
\begin{aligned}
\gamma & =\frac{1}{4 A}\left(1+\sqrt{1+\frac{4 A}{3}}\right) \\
\beta & =\frac{\bar{y}}{\gamma} \\
A & =\ln (\bar{y})-\frac{1}{n} \sum_{k=1}^{n} \ln \left(y_{k}\right)
\end{aligned}
$$

em que: $\bar{y}$ é a precipitação decendial média, ln o logaritmo neperiano e n o número de dados.

Para verificar a aderência dos dados estimados aos observados, utilizou-se o teste de aderência de Lilliefors ao nível de 5\% de significância.

Como o teste Lilliefors é adequado apenas para verificar a parte central das distribuições (Sansilogo, 2008), os gráficos Quantil-Quantil foram também utilizados para auxiliar a avaliação do desempenho da Gama, apesar da indicação de que esses gráficos sejam conceituados como métodos qualitativos de verificação do uso de modelos paramétricos (Wilks, 2006).

\section{RESULTADOS E DISCUSSÃO}

As estimativas dos parâmetros $\gamma$ e $\beta$ da Distribuição Gama, a média e mediana de precipitação e probabilidade de zero para cada decêndio são apresentados na Tabela 2. Quando 
Tabela 1 - Município, código, coordenadas geográficas e período de observação de 43 estações meteorológicas do Estado de Mato Grosso.

\begin{tabular}{|c|c|c|c|c|c|}
\hline Estação & Município & Código & Latitude & Longitude & Período \\
\hline 01 & Apiacás & 0957001 & $09^{\circ} 33^{\prime} \mathrm{S}$ & $57^{\circ} 23^{\prime} \mathrm{W}$ & $1982-2011$ \\
\hline 02 & Arenápolis & 1456002 & $14^{\circ} 22^{\prime} \mathrm{S}$ & $56^{\circ} 58^{\prime} \mathrm{W}$ & 1971-1991 \\
\hline 03 & Aripuanã & 1060001 & $10^{\circ} 26^{\prime} \mathrm{S}$ & $60^{\circ} 33^{\prime} \mathrm{W}$ & $1999-2011$ \\
\hline 04 & Barão de Melgaço & 1755003 & $17^{\circ} 12^{\prime} \mathrm{S}$ & $56^{\circ} 59^{\prime} \mathrm{W}$ & $1971-2011$ \\
\hline 05 & Barão de Melgaço & 1756000 & $17^{\circ} 03^{\prime} \mathrm{S}$ & $56^{\circ} 35^{\prime} \mathrm{W}$ & $1968-2011$ \\
\hline 06 & Barão de Melgaço & 1756001 & $17^{\circ} 17^{\prime} \mathrm{S}$ & $56^{\circ} 23^{\prime} \mathrm{W}$ & $1969-2011$ \\
\hline 07 & Barão do Melgaço & 1656003 & $16^{\circ} 55^{\prime} \mathrm{S}$ & $56^{\circ} 13^{\prime} \mathrm{W}$ & $1970-2011$ \\
\hline 08 & Barra do Bugres & 1557005 & $15^{\circ} 05 \mathrm{~S}$ & $57^{\circ} 48^{\prime} \mathrm{W}$ & $1976-2011$ \\
\hline 09 & Cáceres & 1657000 & $16^{\circ} 03 \mathrm{~S}$ & $57^{\circ} 40^{\prime} \mathrm{W}$ & 1912-1999 \\
\hline 10 & Cáceres & 1657004 & $16^{\circ} 02 \mathrm{~S}$ & $57^{\circ} 15^{\prime} \mathrm{W}$ & $1967-2011$ \\
\hline 11 & Campo Novo do Parecis & 1357001 & $13^{\circ} 41^{\prime} \mathrm{S}$ & $57^{\circ} 33^{\prime} \mathrm{W}$ & $2000-2011$ \\
\hline 12 & Chapada dos Guimarães & 1454003 & $14^{\circ} 45^{\prime} \mathrm{S}$ & $54^{\circ} 58^{\prime} \mathrm{W}$ & $1987-2011$ \\
\hline 13 & Colniza & 0958002 & $09^{\circ} 27^{\prime} \mathrm{S}$ & $58^{\circ} 56^{\prime} \mathrm{W}$ & 2000-2011 \\
\hline 14 & Comodoro & 1360003 & $13^{\circ} 43^{\prime} \mathrm{S}$ & $60^{\circ} 35^{\prime} \mathrm{W}$ & $1999-2011$ \\
\hline 15 & Cuiabá & 1556002 & $15^{\circ} 37^{\prime} \mathrm{S}$ & $56^{\circ} 06^{\prime} \mathrm{W}$ & $1911-2010$ \\
\hline 16 & Diamantino & 1553002 & $15^{\circ} 31^{\prime} \mathrm{S}$ & $53^{\circ} 04^{\prime} \mathrm{W}$ & $1922-1998$ \\
\hline 17 & Diamantino & 1256001 & $12^{\circ} 12^{\prime} \mathrm{S}$ & $56^{\circ} 30^{\prime} \mathrm{W}$ & $1975-2007$ \\
\hline 18 & Itiquira & 1754000 & $17^{\circ} 12^{\prime} \mathrm{S}$ & $54^{\circ} 08^{\prime} \mathrm{W}$ & $1965-2011$ \\
\hline 19 & Itiquira & 1754003 & $17^{\circ} 04^{\prime} \mathrm{S}$ & $54^{\circ} 46^{\prime} \mathrm{W}$ & $1970-1989$ \\
\hline 20 & Lucas do Rio Verde & 1256002 & $12^{\circ} 58^{\prime} \mathrm{S}$ & $56^{\circ} 18^{\prime} \mathrm{W}$ & $1999-2011$ \\
\hline 21 & Luciara & 1050000 & $11^{\circ} 13^{\prime} \mathrm{S}$ & $50^{\circ} 40^{\prime} \mathrm{W}$ & $1969-2011$ \\
\hline 22 & Nobres & 1455009 & $14^{\circ} 13^{\prime} \mathrm{S}$ & $55^{\circ} 30^{\prime} \mathrm{W}$ & $2000-2011$ \\
\hline 23 & Nova Brasilândia & 1455010 & $14^{\circ} 46^{\prime} \mathrm{S}$ & $55^{\circ} 13^{\prime} \mathrm{W}$ & $2000-2011$ \\
\hline 24 & Nova Monte Verde & 0957002 & $09^{\circ} 58^{\prime} \mathrm{S}$ & $57^{\circ} 28^{\prime} \mathrm{W}$ & $2000-2011$ \\
\hline 25 & Paranaíta & 0956002 & $09^{\circ} 41^{\prime} \mathrm{S}$ & $56^{\circ} 28^{\prime} \mathrm{W}$ & $1999-2011$ \\
\hline 26 & Pedra Preta & 1654004 & $16^{\circ} 50 ' \mathrm{~S}$ & $54^{\circ} 24^{\prime} \mathrm{W}$ & $1973-2011$ \\
\hline 27 & Poconé & 1757001 & $17^{\circ} 08^{\prime} \mathrm{S}$ & $57^{\circ} 21^{\prime} \mathrm{W}$ & $1968-2011$ \\
\hline 28 & Poconé & 1656001 & $16^{\circ} 30 ' \mathrm{~S}$ & $56^{\circ} 22^{\prime} \mathrm{W}$ & $1968-2011$ \\
\hline 29 & Poconé & 1657001 & $16^{\circ} 48 ' S$ & $57^{\circ} 01^{\prime} \mathrm{W}$ & $1970-1987$ \\
\hline 30 & Porto dos Gaúchos & 1157002 & $11^{\circ} 42^{\prime} \mathrm{S}$ & $57^{\circ} 02^{\prime} \mathrm{W}$ & $1999-2011$ \\
\hline 31 & Poxoréo & 1554001 & $15^{\circ} 51^{\prime} \mathrm{S}$ & $54^{\circ} 22^{\prime} \mathrm{W}$ & 1968-1989 \\
\hline 32 & Poxoréo & 1554004 & $15^{\circ} 49^{\prime} \mathrm{S}$ & $54^{\circ} 22^{\prime} \mathrm{W}$ & $1973-1998$ \\
\hline 33 & Rondonópolis & 1654000 & $16^{\circ} 28 \mathrm{~S}$ & $54^{\circ} 39^{\prime} \mathrm{W}$ & $1965-2011$ \\
\hline 34 & Rosário Oeste & 1456006 & $14^{\circ} 49^{\prime} \mathrm{S}$ & $56^{\circ} 25^{\prime} \mathrm{W}$ & $1942-1983$ \\
\hline 35 & Rosário Oeste & 1455002 & $14^{\circ} 52^{\prime} \mathrm{S}$ & $55^{\circ} 52^{\prime} \mathrm{W}$ & $1968-1982$ \\
\hline 36 & Santo Antônio de Leverger & 1556007 & $15^{\circ} 41^{\prime} \mathrm{S}$ & $56^{\circ} 08^{\prime} \mathrm{W}$ & $1975-2011$ \\
\hline 37 & São Félix do Araguaia & 1151000 & $11^{\circ} 40^{\prime} \mathrm{S}$ & $51^{\circ} 22^{\prime} \mathrm{W}$ & $1983-2011$ \\
\hline 38 & Sapezal & 1358002 & $13^{\circ} 28^{\prime} \mathrm{S}$ & $58^{\circ} 58^{\prime} \mathrm{W}$ & $1983-2011$ \\
\hline 39 & Sapezal & 1358005 & $13^{\circ} 54^{\prime} \mathrm{S}$ & $58^{\circ} 53^{\prime} \mathrm{W}$ & $1999-2011$ \\
\hline 40 & Terra Nova do Norte & 1055004 & $10^{\circ} 36^{\prime} \mathrm{S}$ & $55^{\circ} 06^{\prime} \mathrm{W}$ & $2000-2011$ \\
\hline 41 & Vera & 1255000 & $12^{\circ} 17^{\prime} \mathrm{S}$ & $55^{\circ} 17^{\prime} \mathrm{W}$ & $1973-1997$ \\
\hline 42 & Vera & 1254002 & $12^{\circ} 21^{\prime} \mathrm{S}$ & $54^{\circ} 29^{\prime} \mathrm{W}$ & $1997-2011$ \\
\hline 43 & Vila Bela da S. Trindade & 1659001 & $16^{\circ} 16^{\prime} \mathrm{S}$ & $59^{\circ} 29^{\prime} \mathrm{W}$ & $1999-2011$ \\
\hline
\end{tabular}

a coluna do decêndio possui apenas os dados de precipitação (média e mediana) e probabilidades de zero, mas não apresentam as estimativas de $\gamma$ e $\beta$, isto se deu em função da impossibilidade de calcular estes parâmetros em virtude da maioria ou da totalidade dos valores de precipitação ser iguais a zero.

As estimativas do parâmetro $\gamma$ variaram de 0,01 a 120,7 e sua variação não foi a mesma para as estações, tendo parte delas resultado semelhante ao descrito por Murta et al. (2005), Moreira et al. (2010) e Martins et al. (2011), ou seja, os valores de $\gamma$ foram se elevando a medida que o volume de precipitação decendial decrescia. Entretanto, deve-se observar que os estudos acima mencionados realizaram as estimativas de $\gamma$ para dados de precipitações mensais, enquanto no presente estudo as estimativas foram realizadas para dados decendiais.

$\mathrm{Na}$ maioria das estações, as maiores estimativas de $\gamma$ ocorreram para os decêndios mais secos, e dentre eles a maior ocorrência estava entre o décimo sétimo e o décimo nono. Segundo Botelho e Morais (1999), isso ocorre em virtude de uma pronunciada assimetria nos períodos mais secos, pois o parâmetro $\gamma$ é inversamente proporcional à assimetria. Para Blain (2009), os meses que apresentam um elevado valor do parâmetro $\gamma$ indicam distribuições com formas próximas à 
normal, em que elevados totais decendiais de precipitação são esperados. Para as 43 estações do estado de Mato Grosso em estudo, normalmente este período corresponde aos meses de dezembro a março, os quais apresentam os maiores valores de $\gamma$ e, portanto, de maneira geral, os menores graus de assimetria na função de densidade de probabilidade gama (Blain et al., 2007).

De forma geral, como já era esperado, o parâmetro $\beta$ foi maior para os decêndios mais chuvosos e isto ocorreu em virtude do aumento da variabilidade dos dados nestes decêndios. De acordo com Murta et al. (2005), as estimativas da variância aumentam rapidamente com o crescimento do valor de $\beta$, visto que a variância é diretamente proporcional ao quadrado de $\beta$.

Observou-se que o parâmetro $\beta$ apresentou valor inferior a 100 para todos os decêndios exceto para o $1^{\circ}$ da estação $1557005,2^{\circ}$ da estação $1754003,11^{\circ}$ da estação $1255000,17^{\circ}, 18^{\circ}, 31^{\circ}, 32^{\circ}$ e $33^{\circ}$ da estação 1654004 e $32^{\circ}$ da estação 1357001. Dessa forma a quase totalidade dos parâmetros $\beta$ poderá ser utilizada para o cálculo da estimativa das precipitações prováveis através da Distribuição Gama. Desempenho semelhante para a distribuição Gama foi verificado por Moreira et al. (2010) no município de Nova Maringá em Mato Grosso e por Martins et al. (2011) estudando valores de precipitação em oito municípios no arco das nascentes do rio Paraguai em Mato Grosso. Segundo Thom (1958), para valores superiores a 100 não se deve utilizar a Distribuição Gama incompleta.

Observando as maiores precipitações decendiais verifica-se que $65 \%$ das estações avaliadas apresentaram pelo menos um decêndio com mais de $100 \mathrm{~mm}$ de precipitação, sendo a estação 1060001 (Aripuanã) a que apresentou o maior número de decêndios com mais de 100 mm (11 decêndios), seguida das estações 957002 (Nova Monte Verde) e 956002 (Paranaíta), cada uma com 10 decêndios. Moreira et al. (2010) também encontraram alguns decêndios com precipitação acima de 100 mm para o município de Nova Maringá em Mato Grosso.

Considerando-se como decêndio seco (precipitação não significativa) aquele que apresentou precipitação média inferior a $10 \mathrm{~mm}$. Observando a Tabela 2, verifica-se que $25 \%$ das estações apresentaram oito decêndios com menos de $10 \mathrm{~mm}$, porém este número variou de 1 a 14 decêndios por estação, tendo ocorrido o menor número na estação 1654004 (Pedra Preta) e o maior na estação 1254002 (Vera). Considerando-se o valor da mediana e não da média, estes números elevam-se.

Segundo Bernardo et al. (2008), as médias de precipitações ocorridas, juntamente com o nível de probabilidade, são de grande importância na tomada de decisão pelos agricultores no manejo de irrigação em meses de veranico, pois estes se dão em função da má distribuição das chuvas dentro de um determinado período (Kumar e Rao, 2007). Diversos autores utilizaram ou recomendaram a precipitação mínima esperada em três anos de cada quatro, isto é, a precipitação esperada com $75 \%$ de probabilidade, ou terceiro quantil, como o sendo o total de chuva que deve ser considerado para o planejamento de atividades agrícolas (Medina e Leite, 1984; Rebello e Almeida, 1986; Gomes, 2001; Bernardo et al., 2008, Danfá et al., 2011).

$\mathrm{Na}$ análise da distribuição pluviométrica decendial (Tabela 2) nota-se que as estações situadas na região norte do estado de Mato Grosso apresentaram a partir do vigésimo nono decêndio precipitação pluviométrica superior a $50 \mathrm{~mm}$, enquanto que estações mais ao sul do estado apresentaram esse volume de precipitação a partir do trigésimo primeiro decêndio. Este período de decêndios com mais de $50 \mathrm{~mm}$ se estende até o nono ou décimo decêndio do ano seguinte, tendo variado entre $11 \mathrm{e}$ 20 decêndios. Foi identificado que as estações da região sul do estado, particularmente as que estão no pantanal, apresentaram menor período com chuvas mais acentuadas. Martins et al. (2011), também observaram que os municípios mais ao sul do estado de Mato Grosso apresentavam menor volume de precipitação pluviométrica quando comparados aos municípios mais ao norte no mesmo período do ano, e ainda segundo estes autores há uma correlação entre precipitação e altitude.

A partir do décimo primeiro ou décimo segundo decêndio observou-se uma queda acentuada na precipitação, sendo o período entre o décimo sexto e vigésimo quinto decêndio o mais seco e a partir do vigésimo sexto observou-se uma retomada no volume de precipitação. Este resultado também foi observado por Moreira et al. (2010), Dallacort et al. (2011), Martins et al. (2011) em municípios de Mato Grosso e por Fietz et al. (1998) no município de Dourados no Mato Grosso do Sul.

Os dados de precipitação decendial são de grande valia para as atividades agrícolas, porque podem auxiliar na tomada de decisões sobre atividades que são favorecidas por período de estiagem, bem como, aquelas que devem ser realizadas em períodos chuvosos (Fidelis et al., 2003). O conhecimento da distribuição das precipitações fornece subsídio para determinar períodos críticos predominantes numa determinada região e condições de fornecer informações que visem reduzir as consequências causadas pelas flutuações do regime pluviométrico, seja pelo emprego da irrigação ou implantação de culturas adaptadas à sazonalidade deste regime (Andrade et al., 1998)

O período em que ocorreram os maiores índices pluviométricos nas 43 estações analisadas no estado de Mato Grosso situa-se de novembro a março, entretanto nas estações situadas em latitude inferior a $14^{\circ} 00^{\prime} \mathrm{S}$ este período se estende um pouco mais, indo do último decêndio de outubro até o ultimo decêndio de abril. Neste período observa-se a não existência de veranicos e o volume de precipitação é suficiente para plantio das principais espécies cultivadas no Mato Grosso. Estes resultados são concordantes com os obtidos por Martins et al. 
Tabela 2 - Parâmetros estimados (p), da distribuição gama incompleta $(\gamma$ e $\beta)$, média e mediana (Med,) pluviométricas (em mm) e porcentagem de precipitações nulas $(0 \%)$, em cada decêndio, para as 43 estações meteorológicas (E) do estado de Mato Grosso em estudo.

Continua.

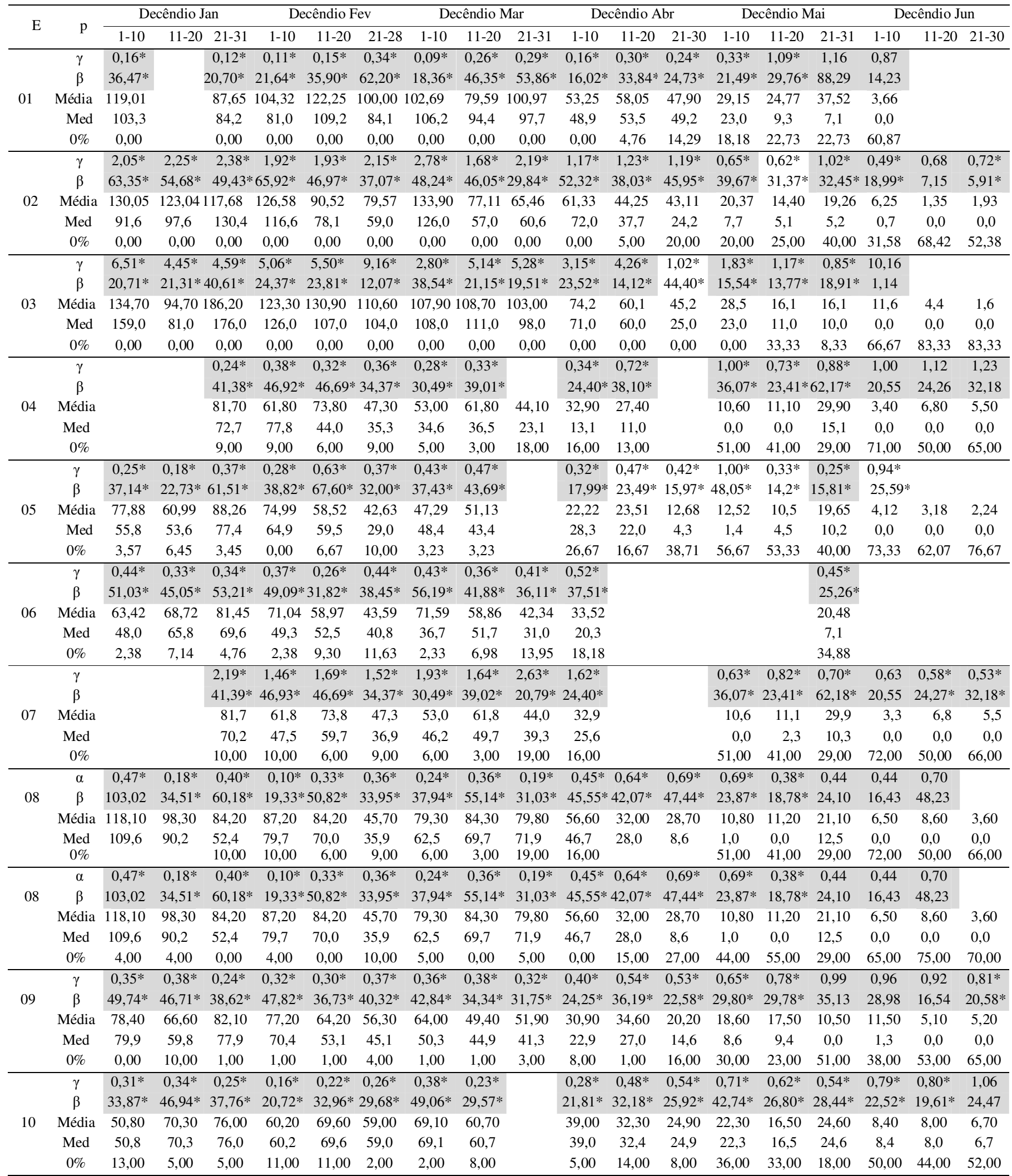


Tabela 2 - Continuação

\begin{tabular}{|c|c|c|c|c|c|c|c|c|c|c|c|c|c|c|c|c|c|c|c|}
\hline \multirow{5}{*}{11} & $\gamma$ & ,64* & $41^{*}$ & $2,83^{*}$ & $1,99^{*}$ & $3,26^{*}$ & $1,89^{*}$ & $2,47^{*}$ & $3,81^{*}$ & $3,03^{*}$ & $1,27^{*}$ & $1,37^{*}$ & $1,28^{*}$ & 4,38 & 1,31 & $1,35^{*}$ & 1,01 & & \\
\hline & $\beta$ & $2,63 *$ & $6,88^{*}$ & $32,78^{*}$ & $47,75^{*}$ & $30,65^{*}$ & $24,69 *$ & $32,21^{*}$ & $27,82 *$ & $32,15^{*}$ & $68,88^{*}$ & $21,59 *$ & $17,39 *$ & 1,488 & 10,10 & $20,49^{*}$ & 10,40 & & \\
\hline & Média & 105,10 & 18,60 & 92,80 & 95,00 & 99,90 & 46,80 & 79,50 & 106,10 & 97,50 & 87,60 & 24,20 & 18,20 & 2,61 & 3,99 & 17,7 & 2,86 & 1,31 & 0,00 \\
\hline & Med & 107,7 & 135,8 & 78,5 & 79,8 & 86,4 & 33,0 & 53,2 & 106,3 & 85,2 & 73,5 & 19,3 & 13,4 & 0,0 & 0,0 & 12,0 & 0,0 & 0,0 & 0,0 \\
\hline & $0 \%$ & 0,00 & 0,00 & 0,00 & 0,00 & 0,00 & 0,00 & 0,00 & 0,00 & 0,00 & 0,00 & 16,67 & 54,55 & 63,64 & 33,33 & 66,67 & 83,33 & 91,67 & 83,33 \\
\hline \multirow{5}{*}{12} & $\gamma$ & $1,52^{*}$ & $2,51 *$ & $1,62^{*}$ & $3,77 *$ & $3,76^{*}$ & $3,57 *$ & $2,58^{*}$ & $1,89^{*}$ & $1,39^{*}$ & $1,62^{*}$ & $0,88^{*}$ & $1,01^{*}$ & $2,72^{*}$ & $0,93^{*}$ & $0,71^{*}$ & 5,26 & 1,58 & 18,43 \\
\hline & $\beta$ & $90,92 *$ & $38,39 *$ & $61,95^{*}$ & $24,88^{*}$ & $22,87 *$ & $23,33 *$ & $26,91 *$ & $39,47 *$ & $71,10^{*}$ & $35,76 *$ & $46,15^{*}$ & $19,66 *$ & $8,21 *$ & $7,90^{*}$ & $17,80^{*}$ & 1,37 & 22,24 & 0,24 \\
\hline & Média & 138,70 & 96,70 & 100,80 & 93,90 & 86,10 & 83,30 & 69,60 & 74,80 & 99,30 & 58,00 & 29,60 & 18,00 & 16,80 & 4,30 & 8,50 & 1,80 & 5,90 & 0,80 \\
\hline & Med & 125,3 & 98,2 & 87,7 & 109,1 & 81,6 & 78,2 & 67,5 & 78,4 & 99,5 & 50,3 & 15,8 & 10,7 & 10,8 & 0,2 & 0,5 & 0,0 & 0,0 & 0,0 \\
\hline & $0 \%$ & 0,00 & 0,00 & 0,00 & 0,00 & 0,00 & 0,00 & 0,00 & 0,00 & 0,00 & 0,00 & 25,00 & 8,33 & 23,08 & 38,46 & 30,77 & 69,23 & 76,92 & 76,92 \\
\hline \multirow{5}{*}{13} & $\gamma$ & $0,16^{*}$ & $0,03 *$ & $0,11^{*}$ & $0,10^{*}$ & $0,18^{*}$ & $0,25^{*}$ & $0,19^{*}$ & $0,13^{*}$ & $0,06^{*}$ & $0,08^{*}$ & $0,46^{*}$ & $0,46^{*}$ & $0,20 *$ & $0,22^{*}$ & 0,05 & 0,51 & & 0,30 \\
\hline & $\beta$ & $39,38^{*}$ & $6,44 *$ & $27,76^{*}$ & $21,64 *$ & $38,28 *$ & $41,24^{*}$ & $33,40^{*}$ & $27,59 *$ & $17,55^{*}$ & $9,77 *$ & $43,11 *$ & $61,69 *$ & $9,40 *$ & $10,20^{*}$ & 3,14 & 14,60 & & 11,48 \\
\hline & Média & 129,30 & 99,20 & 128,30 & 111,30 & 111,50 & 89,90 & 91,40 & 111,83 & 142,50 & 63,70 & 52,60 & 68,10 & 24,70 & 17,60 & 28,60 & 8,98 & 0,20 & 9,60 \\
\hline & Med & 117,7 & 104,3 & 135,2 & 102,4 & 89,9 & 75,8 & 93,0 & 97,6 & 148,9 & 66,9 & 39,3 & 41,0 & 26,2 & 14,6 & 29,8 & 2,5 & 0,0 & 0,0 \\
\hline & $0 \%$ & 0,00 & 0,00 & 0,00 & 0,00 & 0,00 & 0,00 & 0,00 & 0,00 & 0,00 & 0,00 & 0,00 & 9,09 & 0,00 & 27,27 & 9,09 & 41,67 & 83,33 & 50,0 \\
\hline \multirow{5}{*}{14} & $\gamma$ & $2,10 *$ & $3,97 *$ & $8,03^{*}$ & & $3,69^{*}$ & $2,33^{*}$ & $2,19^{*}$ & $5,20^{*}$ & $2,20 *$ & & $0,88^{*}$ & $1,17 *$ & $0,79^{*}$ & 0,47 & $0,69^{*}$ & $1,64^{*}$ & 14, & 15,66 \\
\hline & $\beta$ & $40,91 *$ & $23,45^{*}$ & $12,16^{*}$ & & $26,54 *$ & $=30,15^{*}$ & $27,54^{*}$ & $11,93^{*}$ & $25,10 *$ & & $28,25^{*}$ & $17,52 *$ & $17,36^{*}$ & 31,20 & $49,53 *$ & $3,16^{*}$ & 0,14 & 0,10 \\
\hline & Média & 85,94 & 93,16 & 97,63 & & 97,85 & 70,15 & 60,19 & 62,07 & 55,24 & & 24,93 & 20,45 & 10,01 & 7,95 & 31,11 & 1,42 & 0,39 & 0,29 \\
\hline & Med & 94,3 & 78,9 & 99,0 & & 84,0 & 70,2 & 48,4 & 52,3 & 47,5 & & 19,6 & 14,2 & 3,7 & 0,1 & 11,3 & 0,0 & 0,0 & 0,0 \\
\hline & $0 \%$ & 0,00 & 0,00 & 0,00 & & 0,00 & 0,00 & 0,00 & 0,00 & 0,00 & & 0,00 & 0,00 & 25,00 & 41,67 & 8,33 & 66,67 & 75,00 & 75,00 \\
\hline \multirow{5}{*}{15} & $\gamma$ & & $1,96^{*}$ & $2,33^{*}$ & $2,48^{*}$ & $2,18^{*}$ & $1,67^{*}$ & $1,75^{*}$ & $1,43^{*}$ & $1,42^{*}$ & $1,03 *$ & & $1,29 *$ & $0,80^{*}$ & 0,56 & & 0,54 & 0,49 & 0,45 \\
\hline & $\beta$ & & $30,10 *$ & $32,28 *$ & $30,90^{*}$ & $32,38^{*}$ & $36,06^{*}$ & $41,86^{*}$ & $52,14^{*}$ & $43,77 *$ & $42,51^{*}$ & & $24,95^{*}$ & $25,47 *$ & 36,71 & & 12,83 & 13,51 & 8,63 \\
\hline & Média & & 57,65 & 75,4 & 76,7 & 70,5 & 60,1 & 73,3 & 74,8 & 62,2 & 44,0 & & 31,7 & 18,8 & 20,0 & & 5,9 & & 2,9 \\
\hline & Med & & 52,5 & 65,8 & 65,9 & 70,7 & 50,6 & 70,4 & 60,1 & 45,9 & 35,0 & & 24,1 & 9,3 & 3,8 & & 0,4 & & 0 \\
\hline & $0 \%$ & & 0,00 & 0,00 & 0,00 & 0,00 & 0,00 & 1,47 & 0,00 & 0,00 & 0,00 & & 10,29 & 25,00 & 20,59 & & 39,71 & 51,47 & 54,41 \\
\hline \multirow{5}{*}{16} & $\gamma$ & $2,06^{*}$ & $1,42 *$ & $1,29 *$ & & $1,80^{*}$ & $1,39^{*}$ & $1,70^{*}$ & $0,97^{*}$ & $1,74^{*}$ & & $1,11^{*}$ & $0,98^{*}$ & $0,73^{*}$ & $0,67^{*}$ & $0,50 *$ & $0,58^{*}$ & 3 & 0,62 \\
\hline & $\beta$ & $47,41 *$ & $52,77 *$ & $91,44^{*}$ & & $53,06^{*}$ & $41,98 *$ & $46,22 *$ & $61,07 *$ & $36,65^{*}$ & & $27,43 *$ & $18,05^{*}$ & $20,64^{*}$ & $18,22 *$ & $24,33^{*}$ & $10,53^{*}$ & 22 & 10,94 \\
\hline & Média & 97,59 & 75,08 & 118,31 & & 95,43 & 58,21 & 78,75 & 59,41 & 63,64 & & 30,62 & 16,46 & 14,04 & 11,20 & 8,81 & 3,44 & 2,04 & 1,85 \\
\hline & Med & 82,3 & 58,4 & 87,7 & & 75,8 & 41,4 & 64,0 & 37,7 & 50,1 & & 17,8 & 5,8 & 4,0 & 1,6 & 0,0 & 0,0 & & 0,0 \\
\hline & $0 \%$ & 0,00 & 0,00 & 1,67 & & 3,28 & 6,56 & 0,00 & 4,92 & 3,28 & & 13,33 & 30,00 & 28,33 & 36,67 & 60,00 & 69,49 & 83,05 & 85,00 \\
\hline \multirow{5}{*}{17} & $\gamma$ & $3,08^{*}$ & $3,38^{*}$ & $3,03^{*}$ & $3,84^{*}$ & $4,10^{*}$ & $1,70^{*}$ & $2,45^{*}$ & $3,20^{*}$ & $2,19 *$ & $2,26^{*}$ & $0,67^{*}$ & & $1,46^{*}$ & $0,74^{*}$ & $1,07^{*}$ & 1,13 & 1,09 & $0,47 *$ \\
\hline & $\beta$ & $36,11 *$ & $0,54 *$ & $33,94 *$ & $34,00 *$ & $33,42 *$ & $53,72 *$ & $46,52 *$ & $29,66^{*}$ & $30,55^{*}$ & $26,69^{*}$ & $79,98^{*}$ & & $19,76^{*}$ & $5,79^{*}$ & $10,55^{*}$ & 0,46 & 3,16 & $3,74 *$ \\
\hline & Média & 111,10 & 103,30 & 102,70 & 130,70 & 137,10 & 91,40 & 113,80 & 95,00 & 67,00 & 60,30 & 53,60 & & 28,90 & 4,30 & 11,30 & 0,50 & 3,40 & 1,80 \\
\hline & Med & 100,0 & 99,0 & 94,0 & 131,0 & 116,0 & 70,0 & 102,0 & 89,0 & 67,0 & 52,0 & 38,0 & & 21,0 & 0,0 & 0,0 & 0,0 & 0 & 0,0 \\
\hline & $0 \%$ & 0,00 & 0,00 & 0,00 & 0,00 & 0,00 & 0,00 & 0,00 & 0,00 & 5,56 & 0,00 & 0,00 & & 22,22 & 38,89 & 50,00 & 72,22 & 83,83 & 72,22 \\
\hline \multirow{5}{*}{18} & $\gamma$ & $0,23^{*}$ & $0,22^{*}$ & $0,19 *$ & $0,20 *$ & & & $0,25^{*}$ & $0,23 *$ & $0,20^{*}$ & $0,24 *$ & & $0,30^{*}$ & $0,38^{*}$ & $0,42 *$ & $0,28 *$ & $0,45^{*}$ & 0,8 & $0,43^{*}$ \\
\hline & $\beta$ & $40,89 *$ & $39,63 *$ & $41,89^{*}$ & $42,96 *$ & & & $41,71 *$ & $37,60 *$ & $32,98^{*}$ & $31,94 *$ & & $22,44 *$ & $18,81^{*}$ & $21,42^{*}$ & $15,48^{*}$ & $16,20^{*}$ & $32,06^{*}$ & $16,52^{*}$ \\
\hline & Média & 96,38 & 92,30 & 114,59 & 115,36 & & & 91,14 & 88,44 & 84,87 & 65,81 & & 36,65 & 18,06 & 15,78 & 24,12 & 7,84 & 7,09 & 9,89 \\
\hline & Med & 95,1 & 83,3 & 105,5 & 90,1 & & & 69,2 & 74,0 & 76,8 & 58,7 & & 29,0 & 10,4 & 5,2 & 17, & 0,0 & & 0,0 \\
\hline & $0 \%$ & 0,00 & 2,22 & 0,00 & 0,00 & & & 0,00 & 0,00 & 2,22 & 6,67 & & 8,89 & 34,09 & 43,18 & 18,18 & 60,00 & 66,67 & 53,33 \\
\hline \multirow{5}{*}{19} & $\gamma$ & $0,18^{*}$ & $0,90^{*}$ & $0,72^{*}$ & $0,25^{*}$ & $75^{*}$ & $0,66^{*}$ & $0,28^{*}$ & $0,30^{*}$ & $0,19^{*}$ & $0,58^{*}$ & $0,41^{*}$ & $0,50^{*}$ & $1,11^{*}$ & 1,08 & $0,50^{*}$ & $1,51^{*}$ & $1,18^{*}$ & 0,70 \\
\hline & $\beta$ & $27,1^{*}$ & $117,2 *$ & $93,43 *$ & $49,46^{*}$ & $97,51 *$ & $91,87 *$ & $38,51 *$ & $42,99 *$ & $25,29 *$ & $32,86^{*}$ & $40,17^{*}$ & $25,97 *$ & $40,47^{*}$ & 23,41 & $33,49 *$ & $17,44 *$ & $21,09^{*}$ & 8,89 \\
\hline & Média & 74,33 & 69,12 & 66,07 & 65,64 & 66,48 & 70,04 & 57,80 & 64,94 & 59,88 & 30,05 & 55,32 & 27,45 & 16,20 & 9,57 & 32,06 & 5,47 & 6,24 & 4,07 \\
\hline & Med & 54,1 & & 80,5 & 47,9 & 43,8 & 44,7 & 66,1 & 50,9 & 44,6 & 24,4 & 41,8 & 23,8 & 4,2 & 1,2 & 21,5 & 0,5 & ,2 & 0,4 \\
\hline & $0 \%$ & 7,14 & 14,29 & 14,29 & 35,71 & 14,29 & 14,29 & 21,43 & 14,29 & 14,29 & 6,14 & 0,00 & 7,14 & 28,57 & 28,57 & 14,29 & 28,57 & 42,86 & 42,86 \\
\hline \multirow{5}{*}{20} & $\gamma$ & & $4,97^{*}$ & $3,93^{*}$ & $6,18^{*}$ & $2,50^{*}$ & $4,04 *$ & $2,77 *$ & $2,11^{*}$ & $2,65^{*}$ & $1,66^{*}$ & $1,05^{*}$ & $2,89^{*}$ & $1,34^{*}$ & 1,25 & 0,99 & 0,67 & & 5,09 \\
\hline & $\beta$ & & $6,27 *$ & $28,48^{*}$ & $22,69 *$ & $49,44^{*}$ & $15,75^{*}$ & $36,52 *$ & $35,42 *$ & $34,59 *$ & $37,16^{*}$ & $26,73 *$ & $5,44 *$ & $1,39^{*}$ & 7,69 & 12,19 & 9,87 & & 0,06 \\
\hline & Média & & 80,90 & 111,80 & 140,30 & 123,40 & 63,60 & 101,10 & 74,70 & 91,80 & 61,60 & 28,00 & 15,70 & 1,90 & 9,60 & 12,10 & 6,60 & 2,90 & 0,30 \\
\hline & Med & & 107,0 & 79,0 & 107,0 & 127,0 & 134,0 & & 122,5 & 78,0 & 88,5 & 42,0 & 13,0 & 13,0 & 0,0 & 0,0 & 3,0 & 0,0 & 0,0 \\
\hline & $0 \%$ & & 0,00 & 0,00 & 0,00 & 0,00 & 0,00 & 0,00 & 0,00 & 0,00 & 0,00 & 8,33 & 25,00 & 46,15 & 53,85 & 38,46 & 54,55 & 81,82 & 72,73 \\
\hline & $\gamma$ & & $1,41^{*}$ & $2,34 *$ & $2,14^{*}$ & $2,69^{*}$ & $3,68^{*}$ & $4,51^{*}$ & $1,73^{*}$ & $2,24^{*}$ & $1,29 *$ & $1,15^{*}$ & & $0,73^{*}$ & $1,19^{*}$ & & 3,42 & 1,12 & 1,77 \\
\hline & $\beta$ & $45,19 *$ & $56,28^{*}$ & $32,40 *$ & $40,77^{*}$ & $31,52^{*}$ & $15,21 *$ & $19,34^{*}$ & $50,26^{*}$ & $36,94 *$ & $41,26^{*}$ & $42,61 *$ & & $28,71^{*}$ & $4,76^{*}$ & & 0,75 & 1,12 & 0,38 \\
\hline 21 & Média & 96,70 & 79,50 & 75,80 & 87,30 & 84,80 & 56,00 & 87,30 & 86,90 & 82,70 & 53,30 & 48,90 & & 20,90 & 5,70 & 6,60 & 2,60 & 1,20 & 0,70 \\
\hline & Med & 76,0 & 80,0 & 57,5 & 61,0 & 75,0 & 55,5 & 85,0 & 72,0 & 75,0 & 48,0 & 47,0 & & 8,5 & 0,0 & 0,0 & 0,0 & 0,0 & 0,0 \\
\hline & $0 \%$ & 0,00 & 0,00 & 0,00 & 0,00 & 0,00 & 0,00 & 0,00 & 0,00 & 0,00 & 0,00 & 0,00 & & 0,00 & 51,72 & 58,62 & 86,21 & 86,21 & 89,66 \\
\hline & $\gamma$ & $9,50^{*}$ & $3,76^{*}$ & $2,32 *$ & $1,91^{*}$ & $1,97^{*}$ & $2,97 *$ & $2,57 *$ & $2,20^{*}$ & $2,25^{*}$ & $14,15^{*}$ & $2,06^{*}$ & $2,50^{*}$ & 3,02 & 2,47 & $1,00^{*}$ & & & \\
\hline & $\beta$ & $12,31 *$ & $24,41 *$ & $53,07 *$ & $55,60 *$ & $59,28 *$ & $31,30 *$ & $32,31 *$ & $51,96 *$ & $39,74^{*}$ & $5,07 *$ & $28,44 *$ & $16,29 *$ & 5,80 & 15,22 & $21,19 *$ & & & \\
\hline 22 & Média & 117,03 & 91,75 & 123,35 & 105,92 & 116,97 & 793,11 & 82,90 & 114,32 & 89,43 & 58,75 & 53,67 & 30,58 & 8,77 & 12,51 & 10,64 & 0,00 & 3,60 & 0,00 \\
\hline
\end{tabular}


Tabela 2 - Continuação

\begin{tabular}{|c|c|c|c|c|c|c|c|c|c|c|c|c|c|c|c|c|c|c|c|}
\hline & Med & 128,3 & 90,5 & 116,3 & 65,4 & 91,8 & 72,0 & 75,3 & 105,0 & 78,4 & 64,4 & 43,9 & 31,6 & 2,3 & 0,0 & 1,6 & 0,0 & 0,0 & 0,0 \\
\hline & $0 \%$ & 0,00 & 0,00 & 0,00 & 0,00 & 0,00 & 0,00 & 0,00 & 0,00 & 0,00 & 16,67 & 7,69 & 23,08 & 46,15 & 61,54 & 46,15 & 90,91 & 81,82 & 90,91 \\
\hline \multirow{5}{*}{23} & $\gamma$ & $2,75^{*}$ & $2,90^{*}$ & $1,63^{*}$ & $3,01 *$ & $2,55^{*}$ & $2,63^{*}$ & $4,46^{*}$ & $2,77^{*}$ & $1,50^{*}$ & $4,14^{*}$ & $9,43^{*}$ & $0,88^{*}$ & $2,36^{*}$ & 1,26 & $0,67^{*}$ & $0,41 *$ & & 2,98 \\
\hline & $\beta$ & $37,71^{*}$ & $32,04 *$ & $69,53 *$ & $31,51 *$ & $42,16^{*}$ & $33,01^{*}$ & $16,65^{*}$ & $36,05^{*}$ & $65,73 *$ & $12,26^{*}$ & $4,77 *$ & $39,11^{*}$ & $8,40^{*}$ & 8,62 & $38,54 *$ & $49,12 *$ & & 1,63 \\
\hline & Média & 103,71 & 92,79 & 113,64 & 94,90 & 107,64 & 86,74 & 74,33 & 99,81 & 98,58 & 45,68 & 26,96 & 31,02 & 9,92 & 4,33 & 18,02 & 6,07 & & 0,97 \\
\hline & Med & 73,7 & 101,3 & 93,5 & 96,0 & 102,5 & 63,9 & 59,3 & 88,2 & 66,8 & 41,0 & 31,0 & 18,1 & 2,9 & 0,0 & 3,1 & 0,0 & & 0,0 \\
\hline & $0 \%$ & 0,00 & 0,00 & 0,00 & 0,00 & 0,00 & 0,00 & 0,00 & 0,00 & 0,00 & 9,09 & 36,36 & 9,09 & 45,45 & 54,55 & 27,27 & 63,64 & & 72,73 \\
\hline \multirow{5}{*}{24} & $\gamma$ & $0,17 *$ & $0,23 *$ & $0,08^{*}$ & $0,16^{*}$ & $0,10^{*}$ & $0,37^{*}$ & $0,30^{*}$ & $0,20 *$ & $0,09^{*}$ & & & & & & & 0,15 & & 0,96 \\
\hline & $\beta$ & $44,99 *$ & $48,39 *$ & $24,48^{*}$ & $45,64 *$ & $26,33^{*}$ & $74,97^{*}$ & $53,29 *$ & $47,81 *$ & $23,19 *$ & & & & & & & 6,77 & & 29,07 \\
\hline & Média & 135,49 & 111,29 & 147,17 & 148,90 & 134,77 & 111,64 & 95,38 & 128,00 & 127,80 & & & & & & & 8,39 & 1,58 & 6,93 \\
\hline & Med & 153,2 & 109,9 & 140,1 & 146,6 & 126,4 & 91,1 & 82,3 & 121,6 & 120,9 & & & & & & & 0,0 & 0,0 & 0,0 \\
\hline & $0 \%$ & 0,00 & 0,00 & 0,00 & 0,00 & 0,00 & 0,00 & 0,00 & 0,00 & 0,00 & & & & & & & 58,33 & 83,33 & 58,33 \\
\hline \multirow{5}{*}{25} & $\gamma$ & $0,11^{*}$ & $0,96^{*}$ & $0,15^{*}$ & $0,14^{*}$ & $0,06^{*}$ & $0,15^{*}$ & $0,12^{*}$ & $0,21^{*}$ & $0,10^{*}$ & $0,09 *$ & $0,52 *$ & $0,54 *$ & $0,34^{*}$ & $0,86^{*}$ & $0,58^{*}$ & 1,45 & & 0,77 \\
\hline & $\beta$ & $32,69 *$ & $16,91 *$ & $35,16 *$ & $29,18^{*}$ & $14,78^{*}$ & $24,61 *$ & $30,14 *$ & $51,37 *$ & $22,39 *$ & $12,52 *$ & $56,84 *$ & $44,34 *$ & $18,7^{*}$ & $30,71 *$ & $23,74 *$ & 39,15 & & 6,75 \\
\hline & Média & 163,14 & 91,21 & 124,13 & 112,95 & 117,93 & 88,90 & 130,90 & 130,88 & 118,39 & 73,26 & 62,46 & 47,31 & 30,03 & 12,06 & 17,94 & 7,63 & 4,43 & 0,88 \\
\hline & Med & 161,7 & 108,8 & 111,3 & 104,8 & 109,0 & 95,5 & 127,0 & 123,1 & 127,6 & 68,1 & 50,5 & 40,0 & 15,9 & 0,5 & 7,2 & 0,0 & 0,0 & 0,0 \\
\hline & $0 \%$ & 0,00 & 0,00 & 0,00 & 0,00 & 0,00 & 0,00 & 0,00 & 0,00 & 0,00 & 0,00 & 0,00 & 0,00 & 0,00 & 41,67 & 23,08 & 53,85 & 84,62 & 76,92 \\
\hline \multirow{5}{*}{26} & $\gamma$ & $0,35^{*}$ & $0,33^{*}$ & $0,47^{*}$ & $0,36^{*}$ & $0,44^{*}$ & $0,33^{*}$ & $0,50^{*}$ & $0,53^{*}$ & $0,65^{*}$ & $0,43^{*}$ & $0,61^{*}$ & $0,85^{*}$ & $0,78^{*}$ & $0,66^{*}$ & $1,04^{*}$ & 1,35 & 1,11 & 1,35 \\
\hline & $\beta$ & $45,94 *$ & $52,90 *$ & $76,90 *$ & $65,75^{*}$ & $59,45^{*}$ & $43,43 *$ & $74,78^{*}$ & $71,51 *$ & $71,56^{*}$ & $40,65 *$ & $54,65^{*}$ & $61,30 *$ & $83,40 *$ & $54,89 *$ & $82,32 *$ & 94,24 & 113,881 & 103,83 \\
\hline & Média & 71,00 & 81,80 & 87,10 & 93,40 & 74,30 & 62,70 & 80,40 & 72,70 & 59,40 & 40,90 & 42,80 & 28,00 & 27,10 & 25,70 & 26,40 & 16,70 & 15,20 & 11,90 \\
\hline & Med & 50,8 & 59,4 & 51,1 & 80,4 & 62,2 & 45,5 & 54,1 & 52,2 & 31,7 & 26,5 & 22,8 & 6,0 & 0,0 & 5,3 & 1,1 & 0,0 & 0,0 & 0,0 \\
\hline & $0 \%$ & 0,00 & 5,00 & 5,00 & 5,00 & 2,00 & 10,00 & 5,00 & 5,00 & 7,00 & 22,00 & 17,00 & 35,00 & 56,00 & 46,00 & 46,00 & 62,00 & 75,00 & 30,00 \\
\hline \multirow{5}{*}{27} & $\gamma$ & & $0,27^{*}$ & $0,35^{*}$ & $0,14 *$ & $0,36^{*}$ & $0,46^{*}$ & $0,30^{*}$ & & $0,30^{*}$ & $0,47^{*}$ & $0,64^{*}$ & $0,59 *$ & $0,98^{*}$ & $0,64^{*}$ & $0,35^{*}$ & 1,27 & 0,74 & 0,92 \\
\hline & $\beta$ & & $27,21 *$ & $56,93^{*}$ & $16,61^{*}$ & $45,66^{*}$ & $45,02 *$ & $35,58 *$ & & $29,32 *$ & $33,98 *$ & $40,88^{*}$ & $21,35^{*}$ & $47,94 *$ & $19,79 *$ & $16,26^{*}$ & 12,75 & 17,60 & 22,26 \\
\hline & Média & & 49,30 & 83,10 & 54,60 & 67,30 & 53,50 & 58,80 & & 47,00 & 34,80 & 34,40 & 16,30 & 17,60 & 10,10 & 16,20 & 1,80 & 4,40 & 5,60 \\
\hline & Med & & 57,6 & 45,3 & 69,2 & 97,0 & 30,7 & 34,5 & & 24,1 & 17,1 & 17,3 & 9,2 & 2,3 & 2,0 & 6,6 & 0,0 & 0,0 & 0,0 \\
\hline & $0 \%$ & & 8,00 & 8,00 & 9,00 & 3,00 & 3,00 & 8,00 & & 11,00 & 13,00 & 8,00 & 21,00 & 41,00 & 43,00 & 35,00 & 70,00 & 67,00 & 61,00 \\
\hline \multirow{5}{*}{28} & $\gamma$ & & $1,99 *$ & $1,55^{*}$ & $3,64^{*}$ & $1,52^{*}$ & $1,23^{*}$ & $1,82^{*}$ & & $1,81^{*}$ & $1,20^{*}$ & $0,92 *$ & $0,98^{*}$ & $0,64 *$ & $0,92^{*}$ & $1,56^{*}$ & $0,52^{*}$ & $0,81^{*}$ & $0,68^{*}$ \\
\hline & $\beta$ & & $27,21^{*}$ & $56,93 *$ & $16,61^{*}$ & $45,66^{*}$ & $45,02^{*}$ & $35,59 *$ & & $29,32 *$ & $33,98 *$ & $40,88 * 2$ & $21,35^{*}$ & $47,95^{*}$ & $19,79^{*}$ & $16,27^{*}$ & $12,75^{*}$ & $17,60 *$ & $22,27^{*}$ \\
\hline & Média & & 49,3 & 83,1 & 54,6 & 67,3 & 53,5 & 58,8 & & 47,0 & 34,8 & 34,4 & 16,3 & 17,6 & 10,1 & 16,2 & 1,8 & 4,4 & 5,6 \\
\hline & Med & & 47,8 & 60,2 & 57,2 & 53,8 & 44,2 & 50,4 & & 38,0 & 31,3 & 25,5 & 8,5 & 0,6 & 0,4 & 7,3 & 0,0 & 0,0 & 0,0 \\
\hline & $0 \%$ & & 9,00 & 9,00 & 9,00 & 3,00 & 3,00 & 9,00 & & 11,00 & 14,00 & 8,00 & 22,00 & 42,00 & 43,00 & 35,00 & 70,00 & 67,00 & 61,00 \\
\hline \multirow{5}{*}{29} & $\gamma$ & $1,95^{*}$ & & $1,71^{*}$ & $2,52 *$ & $1,99 *$ & $1,23^{*}$ & $1,22^{*}$ & & & $1,52^{*}$ & $1,12^{*}$ & $1,23^{*}$ & $0,82 *$ & $0,87^{*}$ & & 0,78 & 1,15 & 0,66 \\
\hline & $\beta$ & $52,35 *$ & & $48,45^{*}$ & $33,32 *$ & $51,75^{*}$ & $46,03 *$ & $55,19^{*}$ & & & $30,13^{*}$ & $40,95^{*}$ & $31,11^{*}$ & $29,60^{*}$ & $29,77 *$ & & 19,42 & 12,50 & 16,53 \\
\hline & Média & 102,3 & & 80,6 & 83,9 & 103,0 & 56,7 & 67,4 & & & 43,5 & 43,4 & 28,1 & 15,4 & 14,3 & & 3,9 & 3,3 & 2,8 \\
\hline & Med & 85,4 & & 65,5 & 73,1 & 86,4 & 42,3 & 50,2 & & & 34,2 & 30,7 & 17,5 & 4,8 & 2,4 & & 0,0 & 0,0 & 0,0 \\
\hline & $0 \%$ & 0,00 & & 3,00 & 0,00 & 0,00 & 0,00 & 0,00 & & & 5,00 & 5,00 & 26,00 & 36,00 & 44,00 & & 73,00 & 75,00 & 73,00 \\
\hline \multirow{5}{*}{30} & $\gamma$ & $3,33^{*}$ & $9,91^{*}$ & $3,16^{*}$ & $2,37 *$ & $5,72 *$ & $5,52 *$ & $3,34^{*}$ & $1,80^{*}$ & $3,46^{*}$ & $3,99 *$ & $2,95^{*}$ & $0,99^{*}$ & $0,71^{*}$ & $0,85^{*}$ & $1,02^{*}$ & 2,17 & & 1,25 \\
\hline & $\beta$ & $36,59 *$ & $10,61 *$ & $36,01 *$ & $50,88^{*}$ & $20,89^{*}$ & $12,29^{*}$ & $21,58 *$ & $67,55^{*}$ & $24,55^{*}$ & $17,21^{*}$ & $12,87 *$ & $36,57 *$ & $15,41 *$ & $12,05^{*}$ & $13,92 *$ & 1,03 & & 0,64 \\
\hline & Média & 122,00 & 105,10 & 114,00 & 120,60 & 119,50 & 67,80 & 72,10 & 121,60 & 85,00 & 68,80 & 38,00 & 36,30 & 10,90 & 10,20 & 14,10 & 2,20 & 0,10 & 0,80 \\
\hline & Med & 96,0 & 120,0 & 120,5 & 111,5 & 61,0 & 69,0 & 118,0 & 81,5 & 74,0 & 39,5 & 25,0 & 0,5 & 0,0 & 5,0 & 0,0 & 0,0 & 0,0 & 96,0 \\
\hline & $0 \%$ & 0,00 & 0,00 & 0,00 & 0,00 & 0,00 & 0,00 & 0,00 & 0,00 & 0,00 & 0,00 & 7,69 & 0,00 & 46,15 & 53,88 & 23,08 & 75,00 & 83,33 & 75,00 \\
\hline \multirow{5}{*}{31} & $\gamma$ & $2,67 *$ & $6,04 *$ & $3,40^{*}$ & $3,29^{*}$ & $2,76^{*}$ & $1,64^{*}$ & $2,39^{*}$ & $3,32 *$ & $1,06^{*}$ & $1,23^{*}$ & $0,89^{*}$ & 1,15 & 0,84 & 0,77 & 0,77 & 0,94 & 3,18 & 1,01 \\
\hline & $\beta$ & $42,59 *$ & $13,79 *$ & $32,12 *$ & $23,45^{*}$ & $37,85^{*}$ & $38,41 *$ & $39,40 *$ & $25,48^{*}$ & $70,62^{*}$ & $33,00^{*}$ & $45,82^{*}$ & 29,75 & 26,50 & 13,62 & 34,94 & 4,60 & 1,16 & 5,81 \\
\hline & Média & 113,76 & 83,29 & 109,30 & 82,08 & 104,64 & 66,84 & 94,16 & 89,99 & 79,38 & 40,54 & 43,26 & 36,33 & 29,65 & 14,04 & 46,90 & 7,05 & 8,30 & 10,78 \\
\hline & Med & 71,4 & 84,1 & 85,2 & 82,5 & 36,9 & 106,8 & 75,1 & 61,0 & 26,2 & 23,2 & 22,4 & 11,2 & 0,5 & 0,0 & 0,0 & 0,0 & 0,0 & 71,4 \\
\hline & $0 \%$ & 0,00 & 0,00 & 0,00 & 5,56 & 0,00 & 5,56 & 0,00 & 5,56 & 5,56 & 0,00 & 5,56 & 5,56 & 23,56 & 37,50 & 47,06 & 50,00 & 72,22 & 61,11 \\
\hline \multirow{5}{*}{32} & $\gamma$ & $2,38^{*}$ & $1,91^{*}$ & $2,30^{*}$ & $2,81 *$ & $2,86^{*}$ & $1,77 *$ & $2,02^{*}$ & $2,20^{*}$ & $1,23^{*}$ & $3,25^{*}$ & $0,98^{*}$ & $1,71 *$ & $1,99 *$ & 0,85 & $1,17^{*}$ & $1,81^{*}$ & 1,12 & 1,09 \\
\hline & $\beta$ & $45,11 *$ & $62,78^{*}$ & $36,29 *$ & $39,11 *$ & $31,85^{*}$ & $43,96 *$ & $43,13 *$ & $40,11^{*}$ & $66,61^{*}$ & $12,32 *$ & $48,45^{*}$ & $16,56^{*}$ & $18,43^{*}$ & 12,79 & $14,48^{*}$ & $8,28^{*}$ & 3,20 & 7,90 \\
\hline & Média & 107,55 & 119,72 & 83,37 & 109,74 & 91,14 & 77,71 & 87,14 & 88,08 & 81,76 & 40,03 & 47,33 & 28,37 & 34,21 & 10,09 & 16,90 & 9,97 & 1,68 & 4,33 \\
\hline & Med & 106,6 & 77,4 & 115,9 & 76,5 & 67,0 & 74,9 & 78,0 & 70,0 & 28,3 & 49,3 & 23,2 & 35,8 & 3,4 & 8,6 & 0,0 & 0,0 & 0,0 & 106,6 \\
\hline & $0 \%$ & 0,00 & 0,00 & 5,56 & 0,00 & 0,00 & 0,00 & 0,00 & 0,00 & 0,00 & 0,00 & 12,50 & 12,50 & 18,75 & 21,43 & 18,75 & 56,25 & 68,75 & 64,71 \\
\hline & $\gamma$ & $0,28^{*}$ & $0,21^{*}$ & $0,22^{*}$ & $0,18^{*}$ & $0,26^{*}$ & $0,31^{*}$ & $0,31^{*}$ & $0,40^{*}$ & $0,48^{*}$ & 0,53 & $0,33^{*}$ & $0,50^{*}$ & 0,91 & 1,04 & $0,94^{*}$ & 0,52 & 1,25 & 0,57 \\
\hline & $\beta$ & $47,61 *$ & $35,63 *$ & $33,33 *$ & $29,62 *$ & $38,41^{*}$ & $29,34 *$ & $39,29 *$ & $42,37 *$ & $41,66^{*}$ & 34,48 & $23,56^{*}$ & $24,68^{*}$ & 36,78 & 32,06 & $43,33^{*}$ & 12,25 & 57,53 & 13,27 \\
\hline 33 & Média & 89,20 & 87,70 & 77,80 & 81,00 & 77,60 & 50,70 & 66,00 & 58,30 & 48,10 & 34,40 & 34,70 & 19,90 & 16,80 & 9,80 & 18,50 & 3,90 & 5,80 & 3,90 \\
\hline & Med & 77,4 & 72,4 & 67,5 & 65,0 & 43,5 & 57,3 & 54,3 & 36,1 & 26,1 & 32,8 & 16,2 & 3,6 & 0,1 & 3,0 & 0,0 & 0,0 & 0,0 & 77,4 \\
\hline & $0 \%$ & 1,00 & 2,00 & 0,00 & 2,00 & 0,00 & 0,00 & 2,00 & 0,00 & 2,00 & 7,00 & 9,00 & 28,00 & 32,00 & 48,00 & 34,00 & 69,00 & 79,00 & 69,00 \\
\hline & $\gamma$ & $1,94^{*}$ & $2,62^{*}$ & $2,31^{*}$ & & $3,31^{*}$ & $1,56^{*}$ & $3,06^{*}$ & $3,25^{*}$ & $1,52^{*}$ & $1,37^{*}$ & $1,88^{*}$ & $1,63^{*}$ & $0,88^{*}$ & $1,05^{*}$ & $1,71^{*}$ & & & 1,91 \\
\hline & $\beta$ & $41,48 *$ & $30,72 *$ & $40,37 *$ & & $24,72 *$ & $42,64 *$ & $29,65 *$ & $29,74^{*}$ & $41,00^{*}$ & $39,16^{*}$ & $17,26^{*}$ & $14,48^{*}$ & $13,45^{*}$ & $10,33 *$ & $11,26^{*}$ & & & 0,13 \\
\hline
\end{tabular}


Tabela 2 - Continuação

\begin{tabular}{|c|c|c|c|c|c|c|c|c|c|c|c|c|c|c|c|c|c|c|c|}
\hline 34 & Média & 80,50 & 80,50 & 93,10 & & 81,70 & 66,50 & 90,60 & 96,70 & 62,30 & 53,80 & 32,40 & 23,60 & 11,80 & 10,80 & 19,20 & & & 0,30 \\
\hline \multirow{4}{*}{35} & $\gamma$ & $2,26^{*}$ & $5,30^{*}$ & $5,47^{*}$ & $4,68^{*}$ & $2,34^{*}$ & $4,09 *$ & $2,10^{*}$ & $2,99^{*}$ & $3,53^{*}$ & $2,58^{*}$ & $2,19 *$ & $1,51^{*}$ & $0,73^{*}$ & $0,94 *$ & $0,61^{*}$ & $2,21 *$ & $1,29 *$ & 0,90 \\
\hline & Média & 123,71 & 77,29 & 92,62 & 115,84 & 74,19 & 57,27 & 77,94 & 81,09 & 72,88 & 37,13 & 44,53 & 20,06 & 18,78 & 13,17 & 11,47 & 4,72 & 3,91 & 6,70 \\
\hline & Med & 69,4 & 82,6 & 110,9 & 69,2 & 57,2 & 76,7 & 72,1 & 60,8 & 30,4 & 30,0 & 10,1 & 0,9 & 4,2 & 0,2 & 0,0 & 0,0 & 0,0 & 69,4 \\
\hline & $0 \%$ & 0,00 & 0,00 & 0,00 & 0,00 & 0,00 & 0,00 & 0,00 & 0,00 & 0,00 & 0,00 & 0,00 & 8,33 & 45,45 & 27,27 & 46,15 & 50,00 & 71,43 & 78,57 \\
\hline \multirow[t]{3}{*}{36} & Média & 96,83 & 74,30 & 92,13 & 57,68 & 62,81 & 65,98 & 72,92 & 72,54 & 64,21 & 38,74 & 45,12 & 35,62 & & 25,26 & & 17,63 & 14,58 & 14,48 \\
\hline & Med & 57,6 & 79,4 & 48,15 & 60,05 & 43,55 & 71,8 & 50,9 & 55,05 & 17 & 11,4 & 17,1 & 0,3 & & 4,5 & & 0,0 & 0,0 & 57,6 \\
\hline & $0 \%$ & 17,24 & 0,00 & 3,45 & 3,70 & 3,70 & 11,11 & 7,41 & 11,11 & 11,11 & 32,14 & 25,00 & 28,57 & & 31,03 & & 71,43 & 75,00 & 74,07 \\
\hline \multirow[b]{3}{*}{37} & $\gamma$ & $6,18^{*}$ & $2,06^{*}$ & & $27,05^{*}$ & $2,27 *$ & $2,26^{*}$ & $3,12 *$ & $3,85^{*}$ & $4,23 *$ & $1,90^{*}$ & $1,39^{*}$ & & $3,45^{*}$ & $2,50 *$ & $1,02^{*}$ & 0,84 & 3,31 & \\
\hline & $\beta$ & $17,00 *$ & $37,86^{*}$ & & $68,64 *$ & $29,06^{*}$ & $28,18^{*}$ & $30,06 *$ & $22,40^{*}$ & $16,65^{*}$ & $25,46^{*}$ & $32,48 *$ & & $5,56 *$ & $4,33^{*}$ & $8,05^{*}$ & 1,26 & 0,27 & \\
\hline & Média & 105,10 & 77,90 & & 2,50 & 66,00 & 63,60 & 93,90 & 86,30 & 70,50 & 48,40 & 45,30 & & 19,20 & 10,80 & 8,20 & 1,10 & 0,90 & 1,40 \\
\hline \multirow[t]{3}{*}{38} & Média & 136,67 & & 125,37 & 128,75 & 132,20 & 97,05 & 113,83 & 103,88 & 127,86 & 88,65 & 51,13 & 42,76 & 27,14 & & 14,61 & 8,14 & 6,20 & 5,81 \\
\hline & Med & 122,7 & & 113,5 & 85,9 & 125,6 & 88,0 & 109,3 & 79,7 & 111,1 & 74,7 & 47,2 & 19,9 & 21,6 & & 8,6 & ,0 & & 0,0 \\
\hline & $0 \%$ & 3,70 & & 0,00 & 0,00 & 0,00 & 0,00 & 0,00 & 0,00 & 0,00 & 0,00 & 0,00 & 14,29 & 21,43 & & 35,71 & 55,56 & 88,46 & 69,23 \\
\hline \multirow{5}{*}{39} & $\gamma$ & $4,66^{*}$ & $2,87^{*}$ & $2,05^{*}$ & $1,72 *$ & $5,67^{*}$ & $3,37^{*}$ & $2,93^{*}$ & $2,84^{*}$ & $1,88^{*}$ & $3,22 *$ & $1,73^{*}$ & $1,41^{*}$ & $1,04 *$ & $1,97 *$ & $2,05^{*}$ & $0,73^{*}$ & & \\
\hline & $\beta$ & $27,07 *$ & $30,82 *$ & $5,81 *$ & $78,20 *$ & $19,57^{*}$ & $22,56^{*}$ & $29,10^{*}$ & $35,08^{*}$ & $52,68^{*}$ & $20,79 *$ & $34,44 *$ & $10,24 *$ & $23,78^{*}$ & $19,44^{*}$ & $9,68^{*}$ & $6,77 *$ & & \\
\hline & Média & 126,26 & 88,44 & 155,06 & 134,40 & 110,93 & 76,07 & 85,13 & 99,46 & 99,06 & 66,92 & 54,02 & 13,15 & 11,25 & 13,90 & 16,20 & 1,98 & 0,19 & 0,54 \\
\hline & Med & 125,2 & 76,1 & 163,1 & 119,2 & 133,9 & 74,8 & 79,7 & 112,7 & 69,9 & 62,2 & 65,2 & 9,6 & 0,0 & 0,0 & 15,6 & 0,0 & 0,0 & 0,0 \\
\hline & $0 \%$ & 0,00 & 0,00 & 0,00 & 0,00 & 0,00 & 0,00 & 0,00 & 0,00 & 0,00 & 0,00 & 8,33 & 8,33 & 50,00 & 58,33 & 16,67 & 54,55 & 83,33 & 83,33 \\
\hline \multirow[b]{3}{*}{40} & $\gamma$ & $4,31^{*}$ & $4,28 *$ & $2,97^{*}$ & $3,55^{*}$ & $6,22^{*}$ & $3,46^{*}$ & $2,77^{*}$ & $3,61^{*}$ & $1,98^{*}$ & $2,46^{*}$ & $1,05^{*}$ & $0,76^{*}$ & $1,28^{*}$ & 0,88 & $1,60^{*}$ & 35,66 & 3,64 & \\
\hline & $\beta$ & $34,77 *$ & $22,59^{*}$ & $47,13^{*}$ & $31,78^{*}$ & $22,03 *$ & $18,58^{*}$ & $33,55^{*}$ & $26,05^{*}$ & $43,92^{*}$ & $30,76^{*}$ & $45,45^{*}$ & $62,36^{*}$ & $22,00^{*}$ & 11,65 & $6,49 *$ & 0,01 & 0,03 & \\
\hline & Média & 149,80 & 96,70 & 140,10 & 112,70 & 137,00 & 64,20 & 93,10 & 94,00 & 87,10 & 75,70 & 47,80 & 47,50 & 28,10 & 10,20 & 10,40 & 0,20 & 0,10 & 0,30 \\
\hline \multirow{4}{*}{42} & $\beta$ & $25,70 *$ & $22,17 *$ & $31,86^{*}$ & $26,25^{*}$ & $36,66^{*}$ & $42,67^{*}$ & $57,24^{*}$ & $59,57^{*}$ & $24,99 *$ & $29,43^{*}$ & $101,4^{*}$ & & & 9,86 & 11,63 & & & 4,77 \\
\hline & Média & 107,00 & 91,70 & 97,40 & 129,90 & 122,20 & 86,90 & 111,20 & 102,90 & 67,70 & 60,40 & 67,60 & & & 6,40 & 8,70 & & 0,00 & 1,80 \\
\hline & Med & 84,5 & 98,5 & 65,0 & 107,0 & 88,5 & 68,0 & 56,0 & 84,0 & 61,0 & 43,0 & 15,5 & & & 0,0 & 0,0 & & 0,0 & 0,0 \\
\hline & $0 \%$ & 0,00 & 0,00 & 0,00 & 0,00 & 0,00 & 0,00 & 0,00 & 0,00 & 0,00 & 0,00 & 0,00 & & & 21,43 & 53,33 & & 93,33 & 73,33 \\
\hline & $\gamma$ & $0,52 *$ & $35 *$ & $23 *$ & $47 *$ & $0,27 *$ & $0,55^{*}$ & $0,64 *$ & & $0,58^{*}$ & & & & & & & 1,16 & 0,35 & 0,03 \\
\hline & $\beta$ & $45,62 *$ & $42,41^{*}$ & $45,03 *$ & $38,8^{*}$ & $52,33 *$ & $65,83^{*}$ & $37,55^{*}$ & & $54,91 *$ & & & & & & & 45,16 & 19,14 & 3,77 \\
\hline 43 & Média & 36,61 & 61,37 & 95,54 & 47,31 & 103,55 & 62,54 & 34,63 & & 55,28 & & & & & & & 9,15 & 8,21 & 11,59 \\
\hline & Med & & & & & & 28,0 & 28,0 & & 24,7 & & & & & & & 0,0 & 0,0 & 0,0 \\
\hline & $0 \%$ & 25,00 & 8,33 & 8,33 & 0,00 & 0,00 & 8,33 & 0,00 & & 0,00 & & & & & & & 58,33 & 66,67 & 75,00 \\
\hline F & $F$ & & ecêndio J & & Dec & cêndio A & & & ecêndio S & & & ecêndio C & & & cêndio $\mathrm{N}$ & & & cêndio D & Dez \\
\hline $\mathrm{L}$ & $\mathbf{r}$ & $1-10$ & $11-20$ & $21-31$ & $1-10$ & $11-20$ & $21-31$ & $1-10$ & $11-20$ & $21-30$ & $1-10$ & $11-20$ & $21-31$ & $1-10$ & $11-20$ & $21-30$ & $1-10$ & $11-20$ & $21-31$ \\
\hline & $\gamma$ & & & $0,87 *$ & & & $0,71 *$ & $0,45^{*}$ & $0,35^{*}$ & $0,44 *$ & $0,29^{*}$ & $0,23 *$ & $0,20^{*}$ & $0,23^{*}$ & $0,08^{*}$ & $0,28^{*}$ & $0,24^{*}$ & $0,21^{*}$ & $0,24^{*}$ \\
\hline & $\beta$ & & & $22,56^{*}$ & & & $22,85^{*}$ & $24,39 *$ & $16,45^{*}$ & $28,09 *$ & $22,48^{*}$ & $22,68 *$ & $33,08^{*}$ & $24,38 *$ & $6,81^{*}$ & $44,34 *$ & $41,99 *$ & $31,42 *$ & $49,38^{*}$ \\
\hline 01 & Média & & & 5,79 & & & 10,13 & 23,78 & 23,67 & 34,20 & 42,33 & 52,74 & 47,11 & 57,46 & 46,36 & 85,57 & 93,19 & 80,33 & 111,38 \\
\hline & Med & & & 0,0 & & & 1,0 & & 23,1 & 29,7 & & 37,0 & 74,9 & 50,5 & 40,9 & 65,6 & 74,8 & 83,5 & 102,8 \\
\hline & $0 \%$ & & & 60,87 & & & 45,45 & 21,74 & 8,70 & 4,55 & 42,50 & 0,00 & 0,00 & 0,00 & 0,00 & 0,00 & 0,00 & 0,00 & 0,00 \\
\hline & $\gamma$ & 1,16 & $0,46^{*}$ & 0,91 & 0,91 & 0,99 & $1,08^{*}$ & $0,91^{*}$ & $1,46^{*}$ & & $1,61^{*}$ & $1,82^{*}$ & $1,46^{*}$ & $3,43^{*}$ & $1,25^{*}$ & $3,00^{*}$ & $1,26^{*}$ & $3,15^{*}$ & $3,26^{*}$ \\
\hline & $\beta$ & 16,16 & $18,26^{*}$ & 7,29 & 12,85 & 8,37 & $24,45^{*}$ & $21,37^{*}$ & $11,92^{*}$ & & $30,62 *$ & $24,95^{*}$ & $49,06 *$ & $22,04 *$ & $46,17 *$ & $29,53^{*}$ & $79,52 *$ & $29,74 *$ & $43,09 *$ \\
\hline 02 & Média & 6,88 & 2,19 & 1,74 & 3,08 & 2,61 & 15,29 & 14,63 & 14,80 & & 49,26 & 45,45 & 71,69 & 75,57 & 57,78 & 83,93 & 100,06 & 93,65 & 140,47 \\
\hline & Med & 0,0 & 0,0 & 0,0 & 0,0 & 0,0 & 3,0 & 8,6 & 12,2 & & 32,7 & 36,1 & 74,4 & 70,3 & 58,6 & 89,4 & 88,8 & 86,1 & 136,7 \\
\hline & $0 \%$ & 60,00 & 70,00 & 70,00 & 70,00 & 65,00 & 40,00 & 23,81 & 14,29 & & 0,00 & 0,00 & 0,00 & 0,00 & 0,00 & 5,00 & 0,00 & 0,00 & 0,00 \\
\hline
\end{tabular}


Tabela 2 - Continuação

\begin{tabular}{|c|c|c|c|c|c|c|c|c|c|c|c|c|c|c|c|c|c|c|c|}
\hline \multirow{2}{*}{03} & $\gamma$ & 1,59 & 11,57 & & 1,81 & 4,04 & $1,44^{*}$ & $1,80^{*}$ & $1,93^{*}$ & $2,95^{*}$ & $2,09 *$ & $1,51 *$ & $3,04 *$ & $3,15^{*}$ & $5,95^{*}$ & $3,53^{*}$ & $5,33^{*}$ & $5,26^{*}$ & $3,63^{*}$ \\
\hline & Med & 0,0 & 0,0 & 0,0 & 0,0 & 0,0 & 6,5 & 16,5 & 13,0 & 34,0 & 19,0 & 40,0 & 54,5 & 71,0 & 70,0 & 83,5 & 125,5 & 141,5 & 181,0 \\
\hline \multirow[b]{3}{*}{04} & $\gamma$ & 1,18 & $1,43^{*}$ & 0,56 & 1,01 & & 0,89 & $0,44^{*}$ & $0,53^{*}$ & $0,25^{*}$ & $0,54^{*}$ & $0,28^{*}$ & $0,55^{*}$ & $0,48^{*}$ & $0,36^{*}$ & & $0,31^{*}$ & $0,36^{*}$ & $0,34 *$ \\
\hline & $\beta$ & 48,91 & $23,26^{*}$ & 14,37 & 21,45 & & 26,58 & $15,62^{*}$ & $17,43^{*}$ & $11,85^{*}$ & $26,87^{*}$ & $25,83^{*}$ & $43,22 *$ & $42,58 *$ & $32,84 *$ & & $32,52 *$ & $30,58 *$ & $50,17^{*}$ \\
\hline & Média & 6,30 & 3,30 & 4,50 & 4,00 & 2,80 & 5,90 & 9,40 & 11,00 & 21,10 & 23,80 & 38,60 & 38,70 & 42,80 & 44,70 & & 50,70 & 44,90 & 77,40 \\
\hline \multirow{5}{*}{05} & $\gamma$ & 1,11 & 0,23 & $0,63^{*}$ & $0,49 *$ & & $1,00^{*}$ & $0,81 *$ & $0,43^{*}$ & $0,56^{*}$ & $0,64 *$ & $0,53^{*}$ & $0,23^{*}$ & $0,46^{*}$ & $0,59 *$ & $0,33^{*}$ & $0,29 *$ & $0,34 *$ & $0,28^{*}$ \\
\hline & $\beta$ & 53,54 & 11,98 & $15,00^{*}$ & $8,23 *$ & & $23,42^{*}$ & $36,92 *$ & $16,61^{*}$ & $30,78^{*}$ & $32,72 *$ & $30,60 *$ & $24,21 *$ & $38,45^{*}$ & $48,65^{*}$ & $45,57^{*}$ & $35,49 *$ & $23,87 *$ & $32,15^{*}$ \\
\hline & Média & 6,39 & 7,60 & 3,88 & 2,96 & & 5,58 & 11,84 & 14,58 & 23,62 & 20,98 & 26,67 & 48,87 & 39,11 & 44,40 & 67,11 & 61,61 & 38,27 & 62,50 \\
\hline & & 0,0 & 0,0 & 0,0 & 0,0 & & 0,0 & 0,0 & 6,0 & 16,8 & 10,4 & 26,2 & 32,6 & 37,3 & 31,1 & 55,6 & 51,2 & 52,7 & 72,8 \\
\hline & $\%$ & 76,67 & 70,00 & 70,00 & 66,67 & & 60,00 & 55,17 & 31,03 & 24,14 & 29,63 & 18,52 & 10,71 & 16,67 & 6,90 & 10,34 & 6,90 & 0,00 & 0,00 \\
\hline 06 & $\gamma$ & 0,32 & 0,38 & $0,29 *$ & 0,41 & $0,50^{*}$ & $0,85^{*}$ & $0,63^{*}$ & $0,51 *$ & $0,49^{*}$ & $0,41^{*}$ & $0,47^{*}$ & $0,32 *$ & $0,41^{*}$ & $0,42^{*}$ & $0,28 *$ & $0,47^{*}$ & $0,27 *$ & $0,20^{*}$ \\
\hline \multirow{5}{*}{07} & $\gamma$ & 0,55 & 0,47 & 04 & 0,63 & $1,81^{*}$ & $0,69^{*}$ & $1,26^{*}$ & $1,08^{*}$ & $2,15^{*}$ & $1,07 *$ & $1,90^{*}$ & $1,04^{*}$ & $1,19^{*}$ & $1,52 *$ & & $1,75^{*}$ & $1,52 *$ & $1,60^{*}$ \\
\hline & $\beta$ & 48,91 & 23,26 & 14,37 & 21,46 & $5,59^{*}$ & $26,58 *$ & $15,62^{*}$ & $17,44^{*}$ & $11,86^{*}$ & $26,87^{*}$ & $25,83^{*}$ & $43,23^{*}$ & $42,58 *$ & $32,84 *$ & & $32,52 *$ & $30,59 *$ & $50,18^{*}$ \\
\hline & Média & 6,3 & 3,3 & 4,5 & 4,0 & 2,8 & 5,9 & 9,5 & 11,0 & 21,1 & 23,8 & 38,6 & 38,7 & 42,8 & 44,7 & & 50,7 & 44,9 & 77,4 \\
\hline & ed & 0,0 & 0,0 & 0,0 & 0,0 & 0,0 & 0,0 & 0,0 & 3,8 & 17,9 & 15,3 & 31,1 & 25,2 & 29,5 & 34,7 & & 41,1 & 35,4 & 61,8 \\
\hline & $0 \%$ & 74,00 & 68,00 & 68,00 & 68,00 & 70,00 & 65,00 & 50,00 & 40,00 & 17,00 & 17,00 & 21,00 & 14,00 & 15,00 & 1,00 & & 10,00 & 3,00 & 3,00 \\
\hline \multirow{5}{*}{08} & $\gamma$ & 0,25 & 0,16 & 15 & 0,25 & 0,37 & $0,46^{*}$ & $0,21^{*}$ & $0,51^{*}$ & $0,33^{*}$ & $0,39 *$ & $0,31^{*}$ & $0,27^{*}$ & $0,57^{*}$ & $0,29^{*}$ & $0,39^{*}$ & $0,39 *$ & $0,34^{*}$ & $0,23^{*}$ \\
\hline & $\beta$ & 6,01 & 5,02 & 38 & 10,15 & 5,85 & $9,64^{*}$ & $9,68 *$ & $28,11^{*}$ & $20,06^{*}$ & $25,04 *$ & $27,25^{*}$ & $34,25 *$ & $63,77 *$ & $37,08 *$ & $44,89 *$ & $44,66^{*}$ & $51,91 *$ & $36,14^{*}$ \\
\hline & Média & 2,70 & 4,10 & & 5,60 & 2,80 & 8,40 & 17,80 & 23,10 & 26,70 & 30,10 & 44,70 & 64,10 & 64,90 & 69,60 & 64,40 & 63,30 & 83,10 & 82,80 \\
\hline & & 0,0 & 0,0 & & 0,0 & 0,0 & 4 & 16,4 & 9,7 & 22,2 & 13,4 & 30,6 & 55,0 & 58,9 & 64,1 & 61,1 & 59,1 & 87,9 & 84,2 \\
\hline & $0 \%$ & 75,00 & 70,00 & 0,00 & 70,00 & 65,00 & 26,00 & 25,00 & 25,00 & 20,00 & 14,00 & 4,00 & 0,00 & 0,00 & 0,00 & 0,00 & 0,00 & 0,00 & 0,00 \\
\hline 09 & $\gamma$ & $1,30^{*}$ & 1,07 & & 0,85 & 0,75 & 0,82 & $0,74^{*}$ & 0,73 & $0,54^{*}$ & $0,51^{*}$ & $0,38^{*}$ & $0,56^{*}$ & $0,33^{*}$ &, $36^{*}$ & $0,40 *$ & $0,40^{*}$ & $0,24^{*}$ & $0,26^{*}$ \\
\hline 10 & $0 \%$ & 68,00 & 61,00 & & & & & & & 20,00 & 16,00 & 19,00 & 5,00 & 5,00 & 10,00 & 16,00 & 13,00 & & 5,00 \\
\hline \multirow{5}{*}{11} & $\gamma$ & & & & & & & $*$ & $0,99 *$ & $4,62^{*}$ & $3,03^{*}$ & $1,71^{*}$ & $3,34 *$ & $3,66^{*}$ & $0,81^{*}$ & $4,67^{*}$ & $5,33^{*}$ & $1,73^{*}$ & $4,49 *$ \\
\hline & $\beta$ & & & & 8,92 & & $17,43^{*}$ & $27,14 *$ & $24,56^{*}$ & $7,11^{*}$ & $11,14^{*}$ & $48,41 *$ & $22,55^{*}$ & $16,47^{*}$ & $111,7^{*}$ & $18,99^{*}$ & $19,07 *$ & $49,28^{*}$ & $21,44^{*}$ \\
\hline & Média & 2,23 & 0,22 & & 2,82 & 1,27 & 16,50 & 19,46 & 17,61 & 26,86 & 33,76 & 75,29 & 75,43 & 60,20 & 90,63 & 88,68 & 101,66 & 85,05 & 96,33 \\
\hline & & 0,0 & & & & & & & & 28 & 27,8 & 47,9 & ,9 & 53,0 & 59,1 & 89,8 & 112,2 & 76,5 & 96,4 \\
\hline & 0 & 83,33 & 83,33 & 66,67 & 75,00 & 83,33 & 25,00 & 25,00 & 25,00 & 16,67 & 0,00 & 8,33 & 0,00 & 0,00 & 0,00 & 0,00 & 0,00 & 0,00 & 0,00 \\
\hline & $\gamma$ & 3 & 4,12 & & & & & $40^{*}$ & $1,11^{*}$ & $0,81^{*}$ & $1,17^{*}$ & $2,12 *$ & $3,35^{*}$ & $2,05^{*}$ & $2,23^{*}$ & $2,16^{*}$ & $4,73^{*}$ & $1,66^{*}$ & $8,55^{*}$ \\
\hline & $\beta$ & 4,68 & 10 & & & & 30,31 & $12,95^{*}$ & $23,00^{*}$ & $40,61 *$ & $25,94 *$ & $22,36^{*}$ & $25,30^{*}$ & $36,17 *$ & $24,07^{*}$ & $34,94 *$ & $20,61 *$ & $65,33 *$ & $10,42 *$ \\
\hline 12 & Média & 4,72 & 76 & & 0,51 & 0,48 & 8,48 & 10,56 & 17,02 & 27,26 & 30,27 & 47,47 & 84,76 & 74,32 & 49,51 & 75,35 & 97,58 & 100,37 & 89,05 \\
\hline & & 0,0 & 0 & & 0,0 & 0,0 & & 1,8 & 3,4 & 17,9 & 27,0 & 36,8 & 76,7 & 69,3 & 45,1 & 61,9 & 96,4 & 110,7 & 91,9 \\
\hline & $0 \%$ & 69,23 & 76,92 & 76,92 & 84,62 & 84,62 & 61,54 & 38,46 & 30,77 & 15,38 & 0,00 & 0,00 & 0,00 & 0,00 & 7,14 & 0,00 & 0,00 & 7,14 & 0,00 \\
\hline & & & 0,42 & & 0,12 & 0,88 & $23^{*}$ & $0,33^{*}$ & $0,23^{*}$ & $0,31^{*}$ & $0,24^{*}$ & $0,21 *$ & $0,25^{*}$ & & & & $0,25^{*}$ & $0,10^{*}$ & $0,11^{*}$ \\
\hline & $\beta$ & 63 & 60 & ,79 & 8,31 & 28,12 & $11,28^{*}$ & $20,07 *$ & $11,34^{*}$ & $33,13^{*}$ & $17,26^{*}$ & $17,59^{*}$ & $41,66^{*}$ & & & & $39,20 *$ & $21,71 *$ & $18,96^{*}$ \\
\hline 13 & Média & 2,26 & 5,83 & & 9,53 & 5,42 & & 30,42 & 25,94 & 52,15 & 39,18 & 44,14 & 88,43 & & & & 76,68 & 116,27 & 87,72 \\
\hline & & & & & & 0,0 & & 31,6 & 19,1 & & 32,0 & 34,6 & 63,6 & & & & 63,2 & 119,9 & 97,1 \\
\hline & $0 \%$ & 58,33 & 50,00 & 50,00 & 66,67 & 66,67 & 16,67 & 9,09 & 0,00 & 9,09 & 0,00 & 0,00 & 0,00 & & & & 8,33 & 0,00 & 0,00 \\
\hline & & & & & 0,36 & 3,25 & & $56^{*}$ & $0,79 *$ & $1,76^{*}$ & $1,51^{*}$ & $1,01^{*}$ & $1,91^{*}$ & $1,32 *$ & $1,77^{*}$ & $1,97 *$ & $1,49^{*}$ & $2,95^{*}$ & $5,13^{*}$ \\
\hline & $\beta$ & 30,85 & 36,23 & 10,61 & 32,39 & 7,20 & $15,98 *$ & $23,03^{*}$ & $32,18 *$ & $9,98^{*}$ & $12,72^{*}$ & $36,01 *$ & $26,98^{*}$ & $58,91 *$ & $36,98^{*}$ & $33,51^{*}$ & $41,32 *$ & $22,61 *$ & $14,73^{*}$ \\
\hline 14 & Média & 4,58 & 9,70 & 6,44 & 3,16 & 4,25 & 9,94 & 8,20 & 16,09 & 16,00 & 15,68 & 36,29 & 51,53 & 77,95 & 53,69 & 59,96 & 61,44 & 66,62 & 75,56 \\
\hline & Med & 0,0 & 0,0 & 0,0 & 0,0 & 0,0 & 1,3 & 1,2 & 3,4 & 21,2 & 15,2 & 29,0 & 45,5 & 62,5 & 52,4 & 39,8 & 45,8 & 66,9 & 71,3 \\
\hline & $0 \%$ & 66,67 & 66,67 & 66,67 & 66,67 & 75,00 & 41,67 & 33,33 & 33,33 & 8,33 & 16,67 & 0,00 & 0,00 & 0,00 & 16,67 & 8,33 & 0,00 & 0,00 & 0,00 \\
\hline
\end{tabular}


Tabela 2 - Continuação

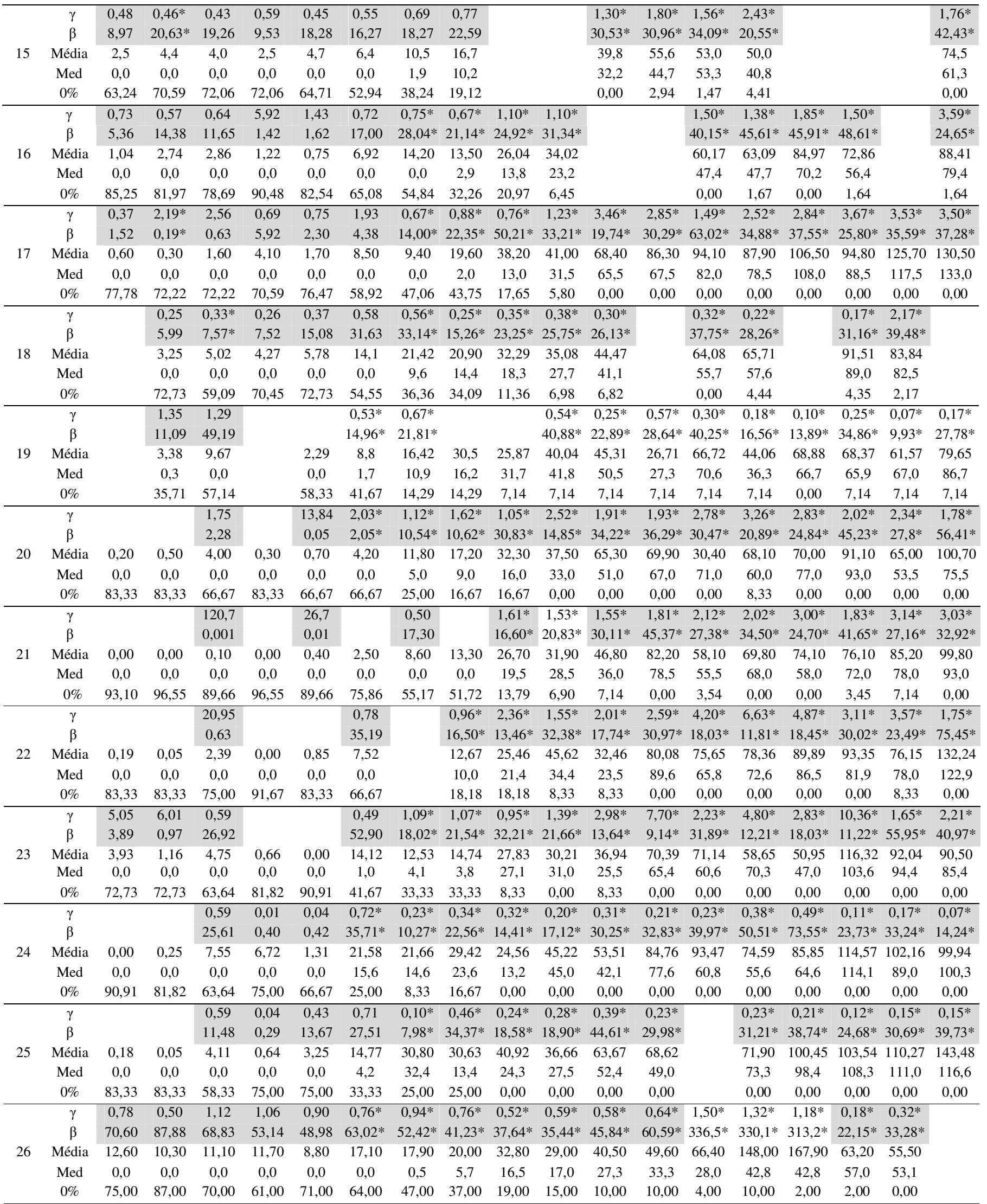


Tabela 2 - Continuação

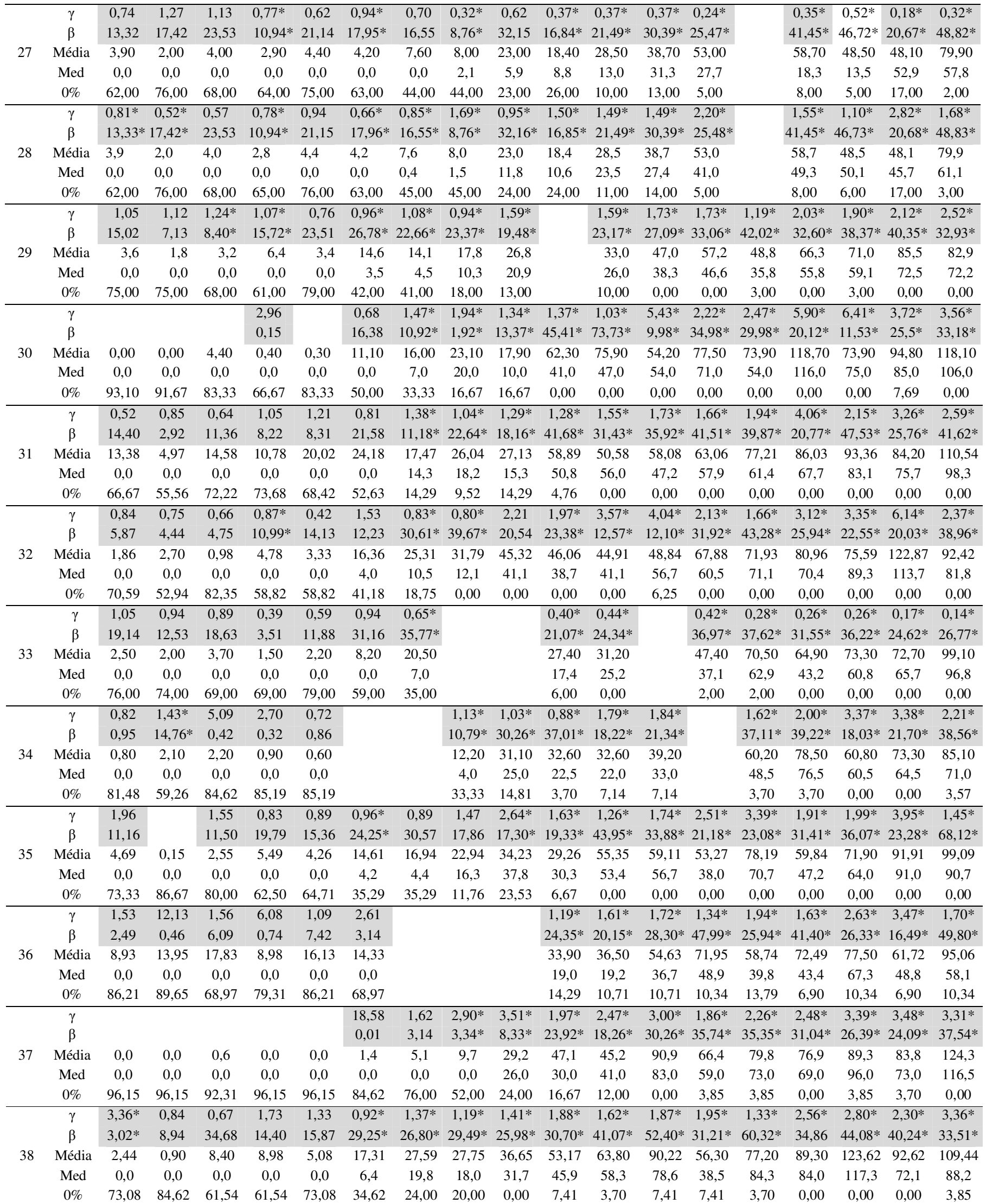


Tabela 2 - Conclusão

\begin{tabular}{|c|c|c|c|c|c|c|c|c|c|c|c|c|c|c|c|c|c|c|c|}
\hline \multirow{5}{*}{39} & $\gamma$ & & 0,81 & 1,68 & 2,77 & 1,16 & 0,97 & $0,89 *$ & $1,04 *$ & $1,74 *$ & $2,84 *$ & $1,21 *$ & $2,90^{*}$ & $1,57 *$ & $1,34^{*}$ & & $2,20^{*}$ & $3,01^{*}$ & $2,75^{*}$ \\
\hline & $\beta$ & & 18,62 & 23,14 & 4,97 & 8,02 & 20,98 & $26,86^{*}$ & $18,59 *$ & $22,27^{*}$ & $11,42 *$ & $22,73 *$ & $23,19 *$ & $44,85^{*}$ & $43,10^{*}$ & & $41,80 *$ & $28,54^{*}$ & $29,33^{*}$ \\
\hline & Média & 0,19 & 2,74 & 21,18 & 3,75 & 3,39 & 9,27 & 14,30 & 15,47 & 38,70 & 32,50 & 27,53 & 67,31 & 70,33 & 57,76 & & 91,80 & 85,91 & 80,75 \\
\hline & Med & 0,0 & 0,0 & 9,8 & 0,0 & 0,0 & 0,0 & 4,3 & 10,9 & 30,4 & 32,8 & 17,9 & 59,1 & 54,3 & 52,7 & & 80,4 & 70,5 & 86,8 \\
\hline & $0 \%$ & 83,33 & 75,00 & 41,67 & 66,67 & 58,33 & 50,00 & 36,36 & 18,18 & 0,00 & 0,00 & 0,00 & 0,00 & 0,00 & 0,00 & & 0,00 & 0,00 & 0,00 \\
\hline \multirow{5}{*}{40} & $\gamma$ & & $0,92^{*}$ & 0,88 & & 0,97 & $0,50^{*}$ & $0,97^{*}$ & 0,81 & & $1,55^{*}$ & $1,30^{*}$ & $2,27^{*}$ & $2,60^{*}$ & $2,70^{*}$ & $5,57^{*}$ & $2,69^{*}$ & $2,70^{*}$ & $11,01^{*}$ \\
\hline & $\beta$ & & $1,72 *$ & 2,52 & & 6,59 & $21,16^{*}$ & $14,36^{*}$ & 8,19 & & $35,41 *$ & $38,99 *$ & $38,76^{*}$ & $29,66^{*}$ & $23,81 *$ & $18,19 *$ & $29,32 *$ & $53,20^{*}$ & $9,82 *$ \\
\hline & Média & 0,80 & 1,60 & 2,20 & 0,00 & 6,40 & 10,60 & 13,90 & 6,60 & & 54,90 & 50,80 & 87,80 & 77,20 & 64,20 & 101,30 & 78,70 & 143,60 & 108,00 \\
\hline & Med & 0,0 & 0,0 & 0,0 & 0,0 & 0,0 & 0,0 & 5,0 & 3,0 & & 32,0 & 44,0 & 92,0 & 78,0 & 48,0 & 97,0 & 49,0 & 97,0 & 109,5 \\
\hline & $0 \%$ & 81,82 & 63,64 & 54,55 & 91,67 & 75,00 & 41,67 & 16,67 & 25,00 & & 0,00 & 0,00 & 0,00 & 0,00 & 0,00 & 0,00 & 0,00 & 0,00 & 0,00 \\
\hline \multirow{5}{*}{41} & $\gamma$ & 1,32 & & 0,47 & & & & 2,08 & $1,89^{*}$ & $0,98^{*}$ & $1,38^{*}$ & $1,45^{*}$ & $2,31 *$ & $2,38^{*}$ & $1,34^{*}$ & $1,58^{*}$ & $3,28^{*}$ & $7,50^{*}$ & $1,52^{*}$ \\
\hline & $\beta$ & 4,75 & & 7,69 & & & & 1,78 & $9,08^{*}$ & $28,86^{*}$ & $18,08^{*}$ & $30,88^{*}$ & $26,74 *$ & $32,80 *$ & $44,56^{*}$ & $45,93 *$ & $27,11 *$ & $12,94 *$ & $61,88^{*}$ \\
\hline & Média & 6,20 & 0,00 & 3,60 & 0,00 & 0,00 & 0,30 & 3,70 & 17,20 & 28,30 & 24,90 & 44,70 & 61,80 & 77,90 & 59,90 & 72,50 & 88,80 & 97,00 & 94,10 \\
\hline & Med & 0,0 & 0,0 & 0,0 & 0,0 & 0,0 & 0,0 & 0,0 & 1,0 & 13,0 & 28,0 & 62,0 & 55,0 & 70,5 & 69,0 & 94,5 & 85,0 & 131,0 & 134,0 \\
\hline & $0 \%$ & 75,00 & 91,67 & 66,67 & 91,67 & 92,31 & 84,62 & 46,15 & 46,15 & 23,08 & 6,67 & 6,67 & 13,13 & 0,00 & 0,00 & 0,00 & 0,00 & 0,00 & 0,00 \\
\hline \multirow{5}{*}{42} & $\gamma$ & 0,37 & 4,62 & 2,11 & 0,72 & 3,08 & 1,76 & $0,79^{*}$ & 1,15 & $0,80^{*}$ & $1,01^{*}$ & $3,81^{*}$ & $2,24 *$ & $1,43^{*}$ & $2,28^{*}$ & $3,18^{*}$ & $2,65^{*}$ & $6,07^{*}$ & $3,44^{*}$ \\
\hline & $\beta$ & 1,72 & 0,06 & 0,59 & 1,22 & 0,09 & 3,65 & $7,38^{*}$ & 6,83 & $44,98 *$ & $36,89 *$ & $14,40^{*}$ & $32,86^{*}$ & $54,22^{*}$ & $30,75^{*}$ & $35,14^{*}$ & $31,76^{*}$ & $22,87^{*}$ & $36,81^{*}$ \\
\hline & Média & 0,60 & 0,30 & 1,30 & 0,90 & 0,30 & 6,40 & 5,80 & 7,90 & 35,80 & 37,30 & 70,10 & 73,50 & 77,50 & 70,20 & 111,70 & 84,20 & 138,70 & 126,70 \\
\hline & Med & 0,0 & 0,0 & 0,0 & 0,0 & 0,0 & 0,0 & 0,5 & 1,5 & 14,0 & 20,0 & 38,0 & 45,5 & 67,0 & 40,0 & 60,0 & 80,0 & 100,0 & 88,0 \\
\hline & $0 \%$ & 75,00 & 75,00 & 76,47 & 80,00 & 80,00 & 66,67 & 50,00 & 42,86 & 14,29 & 6,67 & 0,00 & 0,00 & 0,00 & 0,00 & 0,00 & 0,00 & 0,00 & 0,00 \\
\hline \multirow{5}{*}{43} & $\gamma$ & 0,82 & $0,79^{*}$ & 0,67 & 0,19 & 0,04 & $0,31^{*}$ & $1,11^{*}$ & $0,26^{*}$ & $0,34^{*}$ & $0,14^{*}$ & $0,44^{*}$ & $0,36^{*}$ & $0,35^{*}$ & $0,38^{*}$ & $0,57^{*}$ & $0,09^{*}$ & $0,39^{*}$ & $0,23^{*}$ \\
\hline & $\beta$ & 37,38 & $11,68^{*}$ & 23,55 & 18,3 & 2,16 & $10,91 *$ & $45,56^{*}$ & $21,56^{*}$ & $14,33^{*}$ & $7,22 *$ & $39,9^{*}$ & $39,67 *$ & $48,83^{*}$ & $35,85^{*}$ & $37,13 *$ & $15,42 *$ & $33,17 *$ & $37,00 *$ \\
\hline & Média & 7,56 & 4,90 & 7,62 & 14,04 & 5,50 & 5,23 & 12,02 & 16,00 & 12,69 & 17,24 & 51,11 & 60,52 & 69,97 & 47,92 & 30,10 & 65,51 & 47,09 & 77,69 \\
\hline & Med & 0,0 & 0,3 & 0,0 & 0,0 & 0,0 & 0,0 & 0,0 & 0,0 & 2,3 & 22,0 & 31,1 & 67,3 & 45,4 & 54,4 & 17,6 & 74,4 & 36,3 & 51,1 \\
\hline & $0 \%$ & 66,67 & 45,45 & 58,33 & 66,67 & 75,00 & 66,67 & 50,00 & 58,33 & 41,67 & 33,33 & 0,00 & 0,00 & 8,33 & 8,33 & 18,18 & 25,00 & 0,00 & 8,33 \\
\hline
\end{tabular}

* decêndio com aderência de acordo com gráfico dos quantis-quantis. O fundo em cinza indica aderência de acordo com o teste de Lilliefors.

(2011), que avaliaram o regime de precipitação pluviométrica em oito município do arco das nascentes do Rio Paraguai (MT) e com Martins et al. (2010) que avaliaram a precipitação na microrregião de Tangará da Serra (MT), porém um pouco discordante com Moreira et al. (2010) que avaliando o regime de precipitação no município de Nova Maringá também no estado de Mato Grosso, concluíram que o período chuvoso se estende de outubro a janeiro.

Para Dias et al. (1999), a existência de períodos com baixa precipitação nos meses de inverno é benéfico ao rendimento industrial da cana-de-açúcar. Entretanto, isto contribui de forma significativa para a inviabilização do desenvolvimento de outras atividades agrícolas como, por exemplo, a terceira safra de feijão, a qual na região do Cerrado só é possível através da utilização da irrigação total (Figuerêdo et al., 2008).

De maneira geral observou-se duas épocas ao longo do ano que são bem distintas, uma em que ocorre grande volume de precipitação pluviométrica, considerada chuvosa e outra cujo índice pluviométrico é reduzido, considerada seca. Em geral os padrões das chuvas em Mato Grosso apresentam grande homogeneidade, sendo que os níveis esperados no período chuvoso dificilmente apresentam grandes variações entre os anos, bem como, nos períodos secos, em raros anos, ocorrem precipitações significativas, o que permite um melhor planejamento e garantia de resultados positivos tanto para culturas irrigadas, quanto para as de sequeiro (Martins et al., 2011). Com base neste tipo de informação, que é obtida assumindo-se um nível de probabilidade aceitável ou teoricamente viável, o projetista poderá dimensionar o sistema de irrigação ou o manejo desta. (Junqueira Junior et al., 2007).

De acordo com as análises apresentadas por Zavatini (2009), pode-se inferir que a alternância dos predomínios da massa equatorial continental e da massa polar marítima em duas épocas distintas do ano, é a responsável pela existência de uma época seca e uma chuvosa bem definidas na região.

\section{CONCLUSÕES}

Nas estações pluviométricas analisadas em Mato Grosso, os parâmetros $\gamma$ e $\beta$ da Distribuição Gama e a porcentagem de decêndios sem precipitação pluviométrica $(0 \%)$ apresentados neste trabalho podem ser utilizados para estimar a precipitação decendial, com as probabilidades julgadas adequadas ao planejamento das atividades agrícolas.

Os decêndios com as maiores médias de precipitações estão entre os meses de novembro e março, sendo o maior valor $186,2 \mathrm{~mm}$.

As estações mais ao norte do estado apresentam os decêndios com as maiores precipitações e as estações mais ao sul decêndios com menores precipitações. 


\section{AGRADECIMENTOS}

À Coordenação de Aperfeiçoamento de Pessoal de Nível Superior (CAPES) e ao Conselho Nacional de Desenvolvimento Científico e Tecnológico (CNPq), pelo apoio financeiro, na concessão de bolsas.

\section{REFERÊNCIAS BIBLIOGRÁFICAS}

ANDRADE, C. L. T.; COELHO, E. F.; COUTO, L.; SILVA, E. L. Parâmetros de solo-água para engenharia de irrigação e ambiental. In: FARIA, M. A.; SILVA, E. L.; VILELA, L. A. A.; SILVA, A. M. Manejo de irrigação. Lavras: UFLA/ SBEA, 1998. p.1-132

ASSIS, F. N.; ARRUDA, H. V.; PEREIRA, A. R. Aplicações de estatística à climatologia: teoria e prática. Pelotas: Universidade Federal de Pelotas. 1996. 161p.

BERNARDO, S.; SOARES, A. A.; MANTOVANI, E. C. Manual de irrigação. 8. ed. Viçosa: UFV, 2008.

BLAIN, G. C. Considerações estatísticas relativas à oito séries de precipitação pluvial da Secretaria de Agricultura e Abastecimento do estado de São Paulo. Revista Brasileira de Meteorologia, v.24, n.1, p.12-23, 2009.

BLAIN, G. C.; PIEDADE, S. M. S.; CAMARGO, M. B. P.; GIAROLLA, A. Distribuição temporal da precipitação pluvial mensal observada no posto meteorológico do Instituto Agronômico, em Campinas, SP. Bragantia, v.66, n.2, p.347-355, 2007.

BOTELHO, V. A.; MORAIS, A. R. Estimativa dos parâmetros da distribuição gama de dados pluviométricos do município de Lavras, Estado de Minas Gerais. Ciência e Agrotecnologia, v.23, p.697-706, 1999.

DALLACORT, R.; FREITAS, P. S. L.; GONÇALVES, A. C. A.; FARIA, R. T.; REZENDE, R.; BERTONHA, A. Níveis de probabilidade de rendimento de quatro cultivares de soja em cinco datas de semeadura. Acta Scientiarum Agronomy, v.30, n.2, p. 261-266, 2008.

DALLACORT, R.; MARTINS, J. A.; FREITAS, P. S. L.; COLETTI, A. J. Distribuição das chuvas no município de Tangará da Serra, médio norte do estado de Mato Grosso, Brasil. Acta Scientiarum Agronomy, v.33, n.2, p.193-200, 2011.

DANFÁ, S.; SILVA, A. M.; MELLO, C. R.; COELHO, G.; VIOLA, M. R.; ÁVILA, L. F.. Distribuição espacial de valores prováveis de precipitação pluvial para períodos quinzenais, em Guiné-Bissau. Revista Brasileira de Engenharia Agrícola e Ambiental, v.15, n. 1, p. 67-74, 2011.

DIAS, F. L. F.; MAZZA, J. A.; MATSUOKA, S.; PERECIN, D.; MAULE, R. F. Produtividade da cana-de-açúcar em relação a clima e solos da região noroeste do estado de São Paulo. Revista Brasileira de Ciência do Solo, v.23, n.3, p.627-634, 1999.

ELY, D. F.; ALMEIDA, I. R.; SANT'ANNA NETO, J. L. Variabilidade climática e o rendimento da cultura do milho no estado do Paraná: algumas implicações políticas e econômicas. Geografia, v.12, n.1, p.495-508, 2010.

FIDELIS, R. R.; ROCHA, R. N. C.; LEITE, U. T.; TANCREDI, F. D. Alguns aspectos do plantio direto para a cultura da soja. Bioscience Journal, v.19, n.1, p.23-31, 2003.

FIETZ, C. R.; URCHEI, M. A.; FRIZZONE, J.A.; FOLEGATTI, M. V. Probabilidade de ocorrência de períodos secos e chuvosos na região de Dourados, MS. In: CONGRESSO BRASILEIRO DE AGROMETEOROLOGIA, 1997, Piracicaba. Anais..., v.1, p.101-103, 1997.

FIETZ, C. R.; FRIZZONE, J. A.; FOLEGATTI, M. V.; URCHEI, M. A. Precipitação esperada em diferentes níveis de probabilidade, na região de Dourados, MS. Ciência Rural, v.28, n.1, p.29-34, 1998.

FIGUERÊDO, S. F.; POZZEBON, E. J.; FRIZZONE, J. A.; AZEVEDO, J. A.; GUERRA, A. F.; SILVA, E. M. Gerenciamento da Irrigação do Feijoeiro Baseado em Critérios Técnicos e Econômicos no Cerrado. Irriga, v.13, n.3, p.378-391, 2008.

GOMES, B. M. Comportamento espacial da precipitação decendial (P 75\%) para o Estado de São Paulo. Tese (Doutorado em Agronomia)-Faculdade de Ciências Agronômicas, Universidade Estadual Paulista "Júlio de Mesquita Filho", Botucatu, 2001.

JUNQUEIRA JÚNIOR, J. A.; GOMES, N. M.; MELLO, C. R.; SILVA, A. M. Precipitação provável para a região de Madre de Deus, alto rio grande: modelos de probabilidades e valores característicos. Ciência e Agrotecnologia, v.31, n.3, p.842-850, 2007.

KREPPER, C. M.; SCIAN, B. V.; PIERINI, J. O. Time and space variability of rainfall in central East Argentina. Journal of Climate, v.22, p.39-47, 1989.

KUMAR, K. K.; RAO, T. V. R. Crop growing periods and irrigation needs of corn crop at some stations in Northeast Brazil. Idojaras, v.111, n.1, p 65-77, 2007.

MARTINS, J. A., DALLACORT, R.; INOUE, M. H.; SANTI, A.; KOLlinG, E. M.; COLETTI, A. J. Probabilidade de precipitação para a microrregião de tangará da serra, estado do Mato Grosso. Pesquisa Agropecuária Tropical, v.40, n.3, p.291-296, 2010.

MARTINS, J. A.; DALLACORT, R.; INOUE, M. H.; GALVANIN, E. A. S.; MAGNANI, E. B. Z.; OLIVEIRA, K. C. Caracterização do regime pluviométrico no arco das nascentes do Rio Paraguai. Revista Brasileira de Meteorologia, v.26, n.4, p.639-647, 2011. 
MEDINA, B. F.; LEITE, J. A. Probabilidade de chuva em Boa Vista, RR. Pesquisa Agropecuária Brasileira, v.19, n.11, p.1437-1441, 1984.

MOREIRA, P. S. P.; DALLACORT, R.; MAGALHÃES, R. A.; INOUE, M. H; STIELER, M. C.; SILVA, D. J.; MARTINS, J. A. Distribuição e probabilidade de ocorrência de chuvas no município de Nova Maringá-MT. Revista de Ciências Agro-Ambientais, v.8, n.1, p.9-20, 2010.

MURTA, R. M.; TEODORO, S. M.; BONOMO, P.; CHAVES, M. A. Precipitação pluvial mensal em níveis de probabilidade pela distribuição gama para duas localidades do sudoeste da Bahia. Ciência e Agrotecnologia, v.29, n.5, p.988-994, 2005.

QUEIROZ, E. F.; SILVA, R. J. B.; OLIVEIRA, M. C. N. Modelo de análise de regressão periódica da precipitação mensal, da bacia atlântico sudeste, no Estado do Paraná. Pesquisa Agropecuária Brasileira, v.36, n.5, p.727-742, 2001.
REBELLO, E. R. G.; ALMEIDA, R. M. B.. Probabilidade de ocorrência de chuva mensal em Brasília-DF In: 1 CONNGRESSO INTERAMERICANO DE METEOROLOGIA e 4 CONGRESSO BRASILEIRO DE METEOROLOGIA. Belo Horizonte, 1986 p. 155-159.

SANSIGOLO, C.A. Distribuições de extremos de precipitação diária, temperatura máxima e mínima e velocidade do vento em Piracicaba, SP (1917-2006). Revista Brasileira de Meteorologia, v.23, p.341-346, 2008.

THOM, H.C.S. A note on the gama distribuiton. Monthly Weather Review, v.8, p.117-122, 1958.

WILKS, D S. Statistical Methods in the Atmospheric Sciences. 2. ed. San Diego: Academic Press, 2006. 629 p. ZAVATTINI, J. A. As chuvas e as massas de ar no estado de Mato Grosso do Sul. São Paulo: Editora UNESP, 2009. 212 p. 